\title{
Ties That Bind: Estimating the Natural Rate of Interest for Small Open Economies
}

Valerie Grossman, Enrique Martínez-García, Mark A. Wynne and Ren Zhang

\section{Globalization Institute Working Paper 359}

Research Department

https://doi.org/10.24149/gwp359

Working papers from the Federal Reserve Bank of Dallas are preliminary drafts circulated for professional comment. The views in this paper are those of the authors and do not necessarily reflect the views of the Federal Reserve Bank of Dallas or the Federal Reserve System. Any errors or omissions are the responsibility of the authors. 


\title{
Ties That Bind: Estimating the Natural Rate of Interest for Small Open Economies*
}

\author{
Valerie Grossman ${ }^{\dagger}$, Enrique Martínez-García ${ }^{\ddagger}$, Mark A. Wynne ${ }^{\S}$ and Ren Zhang ${ }^{ \pm}$ \\ First Draft: July 17, 2018 \\ This Draft: March 31, 2019
}

\begin{abstract}
This paper estimates the natural interest rate for six small open economies (Australia, Canada, South Korea, Sweden, Switzerland and the U.K.) with a structural New Keynesian model using Bayesian techniques. Our empirical analysis establishes the following four novel findings: First, we show that the open-economy framework provides a better fit of the data than its closed-economy counterpart for the six countries we investigate. Second, we also show that, in all six countries, a monetary policy rule in which the domestic real policy rate tracks the Wicksellian domestic short-term natural rate fits the data better than an otherwise standard Taylor (1993) rule. Third, we show that over the past 35 years, the natural interest rates in all six countries have shifted downwards and strongly comoved with each other. Fourth, our findings illustrate that foreign output shocks (spillovers from the rest of the world) are a major contributor to the dynamics of the natural rate in these six small open economies, and that natural rates comove strongly with estimated U.S. natural rates.
\end{abstract}

Keywords: Small Open-Economy Model, Monetary Policy, Natural Rate, Bayesian Estimation

JEL Classification: C11, C13, E43, E58, F41

\footnotetext{
*We would like to thank the helpful discussions and suggestions of Nathan S. Balke, Francesco Bianchi, Menzie D. Chinn, Michael B. Devereux, Yue Du, Roberto Duncan, Charles Engel, Marc P. Giannoni, Kathryn Holston, Evan Koenig, Thomas Laubach, Karel Mertens, Marco Del Negro, John C. Williams, Kei-Mu Yi, and many seminar and conference participants at the Federal Reserve Bank of Dallas, University of North Florida, University of Ohio, and the 2018 Northeast Ohio Economics Workshop. We also appreciate Justin Lee for his assistance, Vasco Cúrdia for generously sharing his Matlab package with us, and Benjamin K. Johannsen and Michael T. Kiley for providing us with an update of their estimates of the U.S. natural rate. Ren Zhang gratefully acknowledges the hospitality of the Research Department of the Federal Reserve Bank of Dallas while working on this project. All remaining errors are ours alone. The views expressed in this paper do not necessarily reflect those of the Federal Reserve Bank of Dallas or the Federal Reserve System.

${ }^{\dagger}$ Valerie Grossman, Federal Reserve Bank of Dallas, 2200 N. Pearl Street, Dallas, TX 75201, Phone: +1 (214) 922-6367. Fax: +1 (214) 922-5194, valerie.grossman@dal.frb.org.

$\ddagger$ Enrique Martínez-García, Federal Reserve Bank of Dallas, 2200 N. Pearl Street, Dallas, TX 75201, Phone: +1 (214) 922-5262. Fax: +1 (214) 922-5194, emg.economics@gmail.com, Webpage: https://sites.google.com/view/emgeconomics.

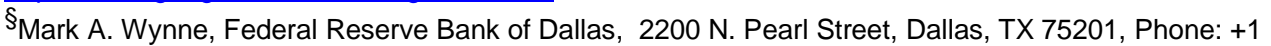
(214) 922-5159. Fax: +1 (214) 922-5194, mark.a.wynne@dal.frb.org.

${ }^{ \pm}$Contacting author: Ren Zhang, Bowling Green State University. Correspondence: Department of Economics, Bowling Green State University, Bowling Green, OH 43403. Phone: +1 (419) 372-2640. Fax: +1(419) 372-1557, renz@bgsu.edu, Webpage: https://renzhang.weebly.com/.
} 


\section{Introduction}

The concept of the natural rate of interest and its role as a benchmark for monetary policy dates back at least to Wicksell (1898), who defined it as the level of "the [real] rate of interest on loans which is neutral with respect to commodity prices and tends neither to increase nor to decrease them." The concept was familiar to mid-twentieth century monetary economists - it played a key role in Milton Friedman's proposal of an analogous natural rate of unemployment - but had largely disappeared from academic discourse since the latter part of the century. After having been out of fashion in mainstream macroeconomics for decades, the notion of the natural rate resurfaced as a central concept in modern monetary policy thinking and practice at the turn of the century, mostly due to two developments.

The first was purely academic, and had to do with the success of the reinterpretation of the concept by Woodford (2003) within the canonical New Keynesian framework which has been very influential in central bank research departments. The second was the extended period of declining interest rates around the world since at least the 1980s-1990s (Bernanke (2015a), Borio et al. (2017)). The low interest rate levels, achieved without creating inflation, led many scholars and policymakers to argue that the natural rate of interest must have declined, either because of the lingering impact of globalization (the savings glut hypothesis), or because of slower productivity growth (the secular stagnation hypothesis) or because of lower labor force growth due to aging populations (the demographics hypothesis) (Bernanke (2015b), Bernanke (2015c), and Bernanke (2015d)).

In this paper we contribute to the ongoing debate on monetary policy and the fundamental drivers of the natural rate of interest by investigating the propagation of foreign shocks and their contribution to the natural rate. We develop a variant of the business cycle model of Gali and Monacelli (2005) and Lubik and Schorfheide (2007) that incorporates exogenous domestic technological progress (trend growth) and a more flexible representation of preferences for domestic households (including a domestic preference shock). Then, we estimate the domestic natural interest rate within our reference model for a sample of six small open economies that includes Australia, Canada, South Korea, Sweden, Switzerland, and the U.K. Our country sample encompasses different geographic regions, levels of development, and notable differences in the degree of openness, all of which introduce distinct sources of cross-sectional variation in the analysis.

We focus on identifying the foreign determinants of the natural rate in small open economies and on international spillovers (contagion) from the rest of the world (and specifically from the U.S.). Estimating our reference model with standard Bayesian techniques, yields the following four major findings:

First, we show by means of Bayesian model comparison that the small open-economy model provides a more empirically plausible framework with which to describe the data than the closed-economy model for all six countries in our sample.

Second, we show, also by model comparison, robust evidence that monetary policy within the general class of linear Taylor (1993) rules tracks the (Wicksellian) short-term natural rate of interest rather than the steady state (long-term) rate featured in Taylor (1993)'s original policy specification. This is the case for all countries in our sample (similar evidence is reported by Cúrdia et al. (2015) for the U.S.), highlighting the fact that the short-term natural rate is significant not just to assess the path (and the stance) of monetary policy but also for its implementation.

Third, the synchronization of nominal interest rates across all countries in our sample is mostly attributable to the strong comovement in the natural rate, while the interest rate gap (monetary policy stance) 
comovement is fairly weak across countries. Recent evidence suggests that the natural rate of the leading advanced economies has declined to historically low and even negative levels over the last two decades (e.g., Holston et al. (2017) and Del Negro et al. (2018)). ${ }^{1}$ Similarly, monetary policy has generally been loose across the small open-economy countries in our sample in recent years, and our evidence suggests that the natural rate comoves positively and quite strongly with a broad range of measures of the U.S. natural rate, providing external validation of international spillovers (contagion). ${ }^{2}$

Forth, foreign output shocks are a very important driver of the natural interest rate (accounting for $13 \%$ to $60 \%$ of the short-term variation and over $60 \%$ of the long-term variation). Our findings suggest that foreign determinants are a major contributor to the natural rate in small open economies around the world.

The remainder paper is structured as follows. In Section 2 we explain how our work fits within the existing literature on estimating the natural rate. Section 3 outlines our benchmark small open-economy model based on the modeling work of Gali and Monacelli (2005) and Lubik and Schorfheide (2007). More details about the building blocks of the model can be found in the Appendix. Section 4 discusses the Bayesian estimation methodology we use in our empirical analysis as well as the choice of relevant priors and data sources. Section 5 reports our main findings regarding the robustness of the small open-economy specification that we adopt as well as the country estimates of the natural rate of interest and the decomposition of fluctuations in the natural rate into its different domestic and global drivers. We also discuss evidence suggestive of crosscountry spillovers from the declining natural rate of major advanced economies - specifically, the U.S.-into the recovered estimates of the natural rate for the diverse group of small open economies that we consider in the paper. Finally, Section 6 concludes by putting our empirical evaluation exercise into perspective in relation to the ongoing debate on the declining natural rates around the world.

\section{Literature Review}

Over the last 15 years or so, various econometric approaches have been proposed to estimate the unobserved (and time-varying) natural rate of interest, which can be broadly divided into three strands: pure timeseries methods, semi-structural methods, and structural methods. Each approach has its advantages and disadvantages.

The first strand relies on pure multivariate time-series models such as the univariate local level model, the time-varying-parameter vector autoregression model, and the multivariate trend-cycle decomposition approach. ${ }^{3}$ Compared to other more structural models, the pure time-series models tend to impose fewer

\footnotetext{
${ }^{1}$ Holston et al. (2017) and Del Negro et al. (2018), among others, suggest that estimated natural rates in a variety of (mostly developed) countries have exhibited similar declining patterns over the past two decades while Wynne and Zhang (2018b) show the same for the world natural rate. Apart from academic research on the global determinants of the natural rate, there is growing awareness among policymakers who recognize the significance of global forces on the domestic natural rate and in domestic monetary policymaking (see, e.g., Williams (2017), Powell (2018)).

${ }^{2}$ To be precise, we use the updated estimates of the U.S. natural rate of interest from Laubach and Williams (2003), Kiley (2015), Lubik and Matthes (2015), Holston et al. (2017), and Johannsen and Mertens (2018).

${ }^{3}$ Lubik and Matthes (2015) estimate a simple time-varying-parameter vector autoregresion model for three macroeconomic variables (GDP growth, inflation, and the real interest rate) and measure the natural interest rate as the conditional long-horizon forecast of the observed real rate. Hamilton et al. (2016) interpret the natural interest rate as a long-run or steady-state safe real rate and infer the time-series measure of the natural rate with a ten-year moving average of the real interest rates. Fiorentini et al. (2018) adopt a local-level model with stochastic volatility to estimate the natural interest rates for 17 advanced economies with over a century of data. Del Negro et al. (2017) and Del Negro et al. (2018) infer the natural interest rate from a spectrum of bond yields with a trend-cycle decomposition approach, while Johannsen and Mertens (2018) adopt a similar methodology but use shadow rates to take into account the period when policy rates became in many countries constrained at their effective-lower bound (ELB) (from 2008 to 2015 or later in some countries).
} 
restrictions, thereby letting the data speak for itself, which generally results in a more flexible estimation of the unobserved natural rate. However, the pure time-series models also arguably result in less precise estimates of the natural rate and produce estimates that rely on atheoretical or non-structural identifying assumptions. This is a particularly significant limitation for our purposes because by leaving largely unmodeled the structural relationships between natural interest rates, inflation, and output, makes it difficult to identify the drivers behind the movements in the natural rate. Therefore, our approach in this paper is structural to allow us to incorporate the theoretical cross-equation restrictions to help us with identification.

A second strand of the literature uses semi-structural econometric models in which the natural rate is a latent variable that depends on the trend growth rate of potential output and a unit root process which captures other determinants. The natural interest rate is inferred from the structural relationships that link the output gap, inflation, and the deviation of the real interest rate from its natural level implied by an empirical IS curve and an empirical Phillips curve. This burgeoning strand of the literature was pioneered by the seminal work of Laubach and Williams (2003) which spawned a large subsequent literature. ${ }^{4}$ Most of the early groundwork in this area, such as Laubach and Williams (2003) but also Mesonnier and Renne (2007) and Trehan and $\mathrm{Wu}$ (2007), adopts a closed-economy framework. More recent studies have become more aware and recognize the crucial role that international factors play in determining the domestic natural interest rate. Notably, Holston et al. (2017) uncover a substantial international comovement among the closed-economy natural interest rate estimates of four advanced economies (Canada, the Euro area, the U.S., and the U.K.). This substantial comovement suggests an important role for global factors in shaping trend growth and the natural rates of interest.

Wynne and Zhang (2018a) extend the closed-economy Laubach and Williams (2003) model to a twocountry setup in order to explore the international interaction in the determination of the natural interest rates in Japan and the U.S. Neto and Candido (2018) adopt a similar two-country model and measure the contribution of global factors to the natural interest rate in Brazil. With a multi-country setup, Fries et al. (2018) estimate the natural interest rates for the four largest economies in the euro area (France, Germany, Italy, and Spain), assuming that each national economy is linked to the other three via a trade channel and a productivity channel. Berger and Kempa (2014) and Armelius et al. (2018) apply a semi-structural small open-economy model to estimate the natural interest rate in Canada and Sweden, respectively.

Compared to pure time-series models, the semi-structural approach explicitly models the link between the natural rate and macroeconomic fundamentals and, arguably, in doing so is better suited to recovering the natural rate. As noted in Fiorentini et al. (2018), however, the precision of the unobservable natural rate estimates depends on whether the IS curve or the Phillips curve is flat or not. ${ }^{5}$ The high degree of uncertainty around the natural rate estimates leads to risk management problems for central banks when making monetary policy as addressed in Evans et al. (2016). Apart from that, semi-structural approaches may not suffice to identify the structural driving forces behind the estimated natural rates. For the above-

\footnotetext{
${ }^{4}$ See, e.g., Clark and Kozicki (2005), Trehan and Wu (2007), Kiley (2015), Pescatori and Turunen (2015), and Juselius et al. (2017) for the U.S., Mesonnier and Renne (2007) and Fries et al. (2018) for the euro area, Berger and Kempa (2014) for Canada, Armelius et al. (2018) for Sweden, Neto and Candido (2018) for Brazil, Wynne and Zhang (2018a) for the U.S. and Japan, Holston et al. (2017) for Canada, the euro area, the U.S., and the U.K, and Wynne and Zhang (2018b) for the world and so forth.

${ }^{5}$ Fiorentini et al. (2018)'s survey of the literature highlights that the slope of the IS curve and that of the Phillips curve are usually estimated to be flat. The same conclusion is reached also in a number of the studies mentioned here and even with other econometrics models unrelated to the natural interest rate literature (see, e.g., Nelson (2002), Mavroeidis et al. (2014), and Coibion and Gorodnichenko (2015),).
} 
mentioned reasons, we pursue in this paper a fully structural approach instead as it is more suitable for our purpose.

The third strand of the literature, the one our where paper fits in, relies on structural models which tend to be either dynamic stochastic general equilibrium (DSGE) models in the New Keynesian tradition or overlapping generations (OLG) models. ${ }^{6}$ If properly specified, DSGE models are also convenient in evaluating the underlying forces that contribute to the fluctuations of the natural rate without sacrificing additional precision in the estimation of the natural rate. ${ }^{7}$ DSGE models are also convenient in evaluating the optimal monetary policy response when faced with an increase or a decrease in the natural rate, unlike the pure time-series and even the semi-structural models (Andrade et al. (2018)). We should note, however, that DSGE models generally estimate the business-cycle frequency component in the natural interest rate. This is different from pure time-series models and from the semi-structural methods that, in turn, focus on low-frequency movements of the natural rate. However, the existing studies in the DSGE literature tend to estimate the natural interest rate within a closed-economy setup and only for large economies such as the U.S., the euro area, and Japan.

To our knowledge, our paper is among the first attempts to investigate explicitly the open-economy determinants of the natural rate of interest with a full-fledged, structural small open-economy in line with that of Gali and Monacelli (2005) and Lubik and Schorfheide (2007). Our paper also makes a novel contribution to the structural literature estimating the natural rate of interest for six countries with a small open-economy model that explicitly incorporates domestic growth by modeling exogenous domestic technological progress. Furthermore, ours is also the first paper in the literature to evaluate the extent to which the central banks of a wide range of small open economies tracks the natural interest rate in policymaking (along the lines of what Cúrdia et al. (2015) does for the U.S.).

\section{Benchmark Small Open-Economy Model}

Our benchmark model closely follows the small open-economy setup described in Gali and Monacelli (2005) and the variant of Lubik and Schorfheide (2007). We refer to the Appendix for details on the derivation of the log-linearized equations of the small open-economy framework that we use in this paper. Like its closedeconomy counterparts, the model consists of a forward-looking IS equation and a Phillips curve, which summarize the behavior of the private sector. The model also includes an interest feedback rule capturing the response of monetary policy to economic developments. We consider different specifications of the policy reaction function while retaining the same equilibrium conditions to describe the behavior of the private sector - which, in turn, give rise to different empirical modeling specifications. These alternative policy rules allow us to investigate what role the short-term natural rate and the steady-state (long-term) real rate may have played in anchoring the conduct of monetary policy among small open economies.

Deviating from Gali and Monacelli (2005) and Lubik and Schorfheide (2007), we introduce an underlying non-stationary technology (aggregate TFP) process $A_{t}$ into the baseline small open-economy model to

\footnotetext{
${ }^{6}$ See, e.g., Gagnon et al. (2016), Kara and von Thadden (2016), and Eggertsson et al. (2017) for OLG models; and Andrés et al. (2009), Martínez-García and Wynne (2010), Justiniano and Preston (2010), Barsky et al. (2014), Martínez-García (2015), Cúrdia et al. (2015), Hristov (2016), Martínez-García (2017), Del Negro et al. (2017), Hirose and Sunakawa (2017), and Neri and Gerali (2018) for DSGE models.

${ }^{7}$ Martínez-García (2015) and Clarida (2017) show, with a two-country workhorse New Keynesian (DSGE) model, that foreign factors are important determinants of the natural interest rate in open economies. However, they do not provide any quantitative estimates of the natural interest rate.
} 
account for growth — albeit exogenously — while providing a structural representation of the business cycles. In order to guarantee the stationarity of the model, all quantity variables are therefore expressed in terms of percentage deviations with respect to $A_{t}^{\frac{\tau+\tau \varphi}{1+\tau \varphi}}$ where $\varphi>0$ measures the inverse Frisch elasticity of labor supply and $\tau>0$ denotes the intertemporal substitution elasticity. Specifically, the evolution of the small open economy is determined by the following equations.

Optimal saving and consumption behavior produces an Euler equation which can be rewritten as a small open-economy dynamic IS curve:

$$
x_{t}=\mathbb{E}_{t}\left(x_{t+1}\right)-\frac{1}{(1-\alpha) \tau_{\alpha}}\left(i_{t}-\mathbb{E}_{t}\left(\pi_{t+1}\right)-r_{t}^{n}\right)
$$

where $\tau_{\alpha} \equiv \frac{1}{\tau+\alpha(2-\alpha)(\eta-\tau)}, 0<\alpha<1$ measures the degree of openness, $\tau>0$ denotes the intertemporal substitution elasticity, and $\eta>0$ corresponds to the substitutability between domestic and foreign goods from the viewpoint of the domestic household. Equation (1) reduces to its closed-economy variant when $\alpha=0$. The dynamic IS equation states that current real activity, measured by the output gap $x_{t} \equiv y_{A, t}-y_{A, t}^{n}$, depends on expected future real activity, $\mathbb{E}_{t}\left(x_{t+1}\right)$, and on the gap between the ex-ante one-period real interest rate, $i_{t}-\mathbb{E}_{t}\left(\pi_{t+1}\right)$, and its natural level, $r_{t}^{n}$. Here, $i_{t}$ is the nominal (policy) interest rate, $\pi_{t}$ is the CPI inflation rate, $y_{A, t}$ is real output, and $y_{A, t}^{n}$ is the potential output, the level of output that would prevail in the absence of nominal rigidities and under perfect competition.

The potential output of the domestic economy, $y_{A, t}^{n}$, depends on the stationarized rest-of-the-world output, $y_{A, t}^{f}$, as follows:

$$
y_{A, t}^{n}=-\Gamma_{*} y_{A, t}^{f}
$$

where $\Gamma_{*} \equiv \frac{1-\tau \tau_{\alpha}}{\tau \tau_{\alpha}+\tau \varphi}$ is non-negative as long as $\eta>\tau$, and equals $\Gamma_{*}=0$ when $\alpha=0$. We interpret (2) as saying that domestic output potential fluctuations that are not the result of fluctuations in domestic productivity are attributed to movements in the foreign output potential when they are out of step with those from domestic productivity. Following Lubik and Schorfheide (2007), we assume that the rest-of-the-world (foreign) output, $y_{A, t}^{f}$, is exogenous and follows an $\operatorname{AR}(1)$ process.

Given the stationarized potential output, $y_{A, t}^{n}$, the intertemporal Euler equation implies that the natural interest rate, $r_{t}^{n}$, which is the focal point of our analysis, evolves according to:

$$
r_{t}^{n}=\mathbb{E}_{t}\left(\Delta g_{t+1}\right)+\left(\frac{1+\varphi}{1+\tau \varphi}\right) \mathbb{E}_{t}\left(z_{t+1}\right)+\left[\frac{1}{\tau}-(1-\alpha) \tau_{\alpha}\left(\Gamma_{*}+1\right)\right] \mathbb{E}_{t}\left(\Delta y_{A, t+1}^{f}\right)
$$

Furthermore, we assume that the intertemporal taste (or preference) shock, $g_{t}$, and the domestic technology growth shock, $z_{t} \equiv \ln \left(\frac{A_{t}}{A_{t-1}}\right)$, are $\operatorname{AR}(1)$ processes.

From equation (3), we observe that the natural rate $r_{t}^{n}$ depends positively on the forecastable components of next period's productivity growth, $\mathbb{E}_{t}\left(z_{t+1}\right)$, the expected changes in preferences, $\mathbb{E}_{t}\left(\Delta g_{t+1}\right)$, and expected world output growth, $\mathbb{E}_{t}\left(\Delta y_{A, t+1}^{f}\right)$. Intuitively, an increase in households' desire to consume early, which is captured by a persistent rise in $g_{t}$, puts upward pressure on the domestic natural interest rate, so as to dissuade domestic consumers from acting on their desire to anticipate consumption. Similarly, higher expected productivity growth, measured by $\mathbb{E}_{t}\left(z_{t+1}\right)$, requires steeper consumption profiles, and hence a higher natural rate in equilibrium. Finally, the last term in (3) captures the positive effect on the natural 
rate of a higher expected growth rate of world output. ${ }^{8}$ The contribution of foreign countries depends on the structural parameters, including the degree of openness $0<\alpha<1$, the inverse elasticity of labor supply $\varphi>0$, the elasticity of intertemporal substitution $\tau>0$, and the elasticity of substitution between home and foreign goods $\eta>0$. Notice that expected world output growth, $\mathbb{E}_{t}\left(\Delta y_{A, t+1}^{f}\right)$, drops out from the domestic natural interest rate in (3) if the degree of openness is set to $\alpha=0$.

Optimal price-setting behavior by domestic firms leads to the following small open-economy Phillips curve:

$$
\pi_{t}=\beta \mathbb{E}_{t}\left(\pi_{t+1}\right)+\alpha \beta \mathbb{E}_{t}\left(\Delta q_{t+1}\right)-\alpha \Delta q_{t}+\left(\tau_{\alpha}+\varphi\right) \kappa x_{t}+u_{t},
$$

where the composite parameter $\kappa \equiv \frac{(1-\beta \theta)(1-\theta)}{\theta}$ (related to the slope of the Phillips curve) is a function of the intertemporal discount factor, $0<\beta<1$, and the Calvo (1983) price stickiness parameter, $0<\theta<1$. The Phillips curve relates a measure of current CPI inflation, $\pi_{t}$, to expected future inflation, $\mathbb{E}_{t}\left(\pi_{t+1}\right)$, the domestic output gap, $x_{t}$, the first difference of the terms of trade, $\Delta q_{t} \equiv q_{t}-q_{t-1}$, where the terms of trade $q_{t}$ is defined as the price of home goods in terms of foreign goods, and an $\operatorname{AR}(1)$ cost-push shock, $u_{t}$, generated by exogenous fluctuations in markups. Again, the closed economy variant obtains when $\alpha=0$.

Assuming that relative purchasing power parity (PPP) holds, the nominal exchange rate $s_{t}$ gets factored into the definition of CPI inflation as follows:

$$
\pi_{t}=\Delta s_{t}+(1-\alpha) \Delta q_{t}+\pi_{t}^{f}
$$

where $\pi_{t}^{f}$ is world inflation which we treat as an unobservable and assume it follows an AR(1) process. $^{9}$

To evaluate whether central banks in small open economies tracked their domestic natural interest rates when conducting monetary policy, we estimate our model with three sets of monetary policy rules. We start with a standard Taylor (1993)-type interest rate rule ( $T$ rule), where the central bank adjusts its policy instrument, $i_{t}$, in response to deviations on domestic CPI inflation rate, $\pi_{t}$, and the domestic output gap, $x_{t}::^{10}$

$$
i_{t}=\rho_{i} i_{t-1}+\left(1-\rho_{i}\right)\left(\psi_{x} x_{t}+\psi_{\pi} \pi_{t}\right)+\varepsilon_{i, t},
$$

where the smoothing term is included in the rule with $0<\rho_{i}<1$ to match the persistence in the nominal interest rate. The response to inflation and output gap deviations is given by the parameters $\psi_{\pi}>0$ and $\psi_{x} \geq 0$. Moreover, $\varepsilon_{i, t}$ is an exogenous policy shock which can be interpreted as the non-systematic component of monetary policy. In this case, the policy rate is defined in deviations from its steady state-

\footnotetext{
${ }^{8}$ The coefficient on world output growth, $\mathbb{E}_{t}\left(\Delta y_{A, t+1}^{f}\right)$, is not unambiguously positive. However, for a wide range of conventional values of the corresponding structural parameters, it will indeed be positive.

${ }^{9}$ An alternative interepretation is that $\pi_{t}^{f}$ captures misspecification, or deviations from PPP. Since the other variables in the CPI inflation definition-that is, in equation (5) - are observed, this more general interpretation of $\pi_{t}^{f}$ relaxes the potentially tight restrictions imposed by the PPP assumption on the exchange rate pass-through when subsequently estimating the model.

${ }^{10}$ The New Keynesian concept of the short-term natural rate of interest is that of the real interest rate (the nominal rate less expected inflation) consistent with output at its potential and price stability. Within Woodford (2003)'s framework, the (Wicksellian) short-term natural interest rate is then the short-term real interest rate that would prevail in the economy if all prices and wages are perfectly flexible and all markets operate under perfect competition. Policymakers as well as scholars are therefore keen on estimating the natural rate of interest and identifying its determinants because the natural rate provides a policy reference with which to assess the stance of monetary policy and with which to guide the central bank's actions. Monetary policy sets the short-term nominal interest rate (its main monetary policy instrument) so that the real interest rate tracks its corresponding natural rate as the central bank aims to achieve full employment of resources (see, e.g., Bernanke $(2015 \mathrm{a}))$. Monetary policy is said to be neutral when the real short-term interest rate equals the short-term natural rate, expansionary when it is lower and contractionary when it is higher. Alternatively, a measure of the long-run natural rate can be considered - this is the case of the
} 
which in the zero-inflation steady state equals the steady-state real rate -implicitly setting the long-term real rate as the reference rate for policymaking.

The second rule we study is an alternative policy rule that tracks the short-term natural interest rate rather than the long-term real rate, which is referred as the Wicksellian rule ( $W$ rule) in the terminology of Cúrdia et al. (2015). Following the $W$ rule, the policy rate responds to the domestic natural interest rate, $r_{t}^{n}$, and to domestic inflation, $\pi_{t}$, with some inertia, as in

$$
i_{t}=\rho_{i} i_{t-1}+\left(1-\rho_{i}\right)\left(r_{t}^{n}+\psi_{\pi} \pi_{t}\right)+\varepsilon_{i, t} .
$$

In here, policymakers respond solely to deviations on inflation but $r_{t}^{n}$ is the relevant target for the actual policy rate. When the natural rate rises, say because of a significant adjustment in foreign demand, the actual rate follows, so as to close the interest rate gap, and hence keep output close to its potential level. As in Cúrdia et al. (2015), we also consider (and estimate) the model with a more general rule ( $W \& T$ rule) to explore the possibility that central banks track the short-term natural rate and aim both to close the output gap and tame inflation in order to stabilize the real economy. The $W \& T$ rule is of the form:

$$
i_{t}=\rho_{i} i_{t-1}+\left(1-\rho_{i}\right)\left(r_{t}^{n}+\psi_{x} x_{t}+\psi_{\pi} \pi_{t}\right)+\varepsilon_{i, t}
$$

where natural interest rate $r_{t}^{n}$, domestic output gap $x_{t}$, and domestic inflation are all essential inputs of monetary policy decisions. ${ }^{11}$

The terms of trade, $q_{t}$, is determined endogenously as the relative price that clears international goods markets and, accordingly, is proportional to the scarcity of foreign goods relative to domestic ones. In terms of growth rates, the relationship can be written as:

$$
\Delta q_{t}=\tau_{\alpha}\left(\Delta y_{A, t}^{f}-\Delta y_{A, t}\right)
$$

An increase in world output raises demand for the domestically-produced goods so that the terms of trade (i.e., its relative price) improves, while a decline in domestic output has the opposite effect. Equation (7) implies a tight link between the fluctuations in terms of trade, $\Delta q_{t}$, and the difference between foreign and domestic output growth, $\Delta y_{A, t}^{f}-\Delta y_{A, t}$. We view the foreign output growth, $\Delta y_{A, t}^{f}$, through the lens of our small open-economy model as an exogenous driver $\left(y_{A, t}^{f}\right.$ is an exogenous shock that follows an $\operatorname{AR}(1)$ process) that neither private agents nor policymakers in the home country can influence and ultimately must take as given.

Moreover, we follow Lubik and Schorfheide (2007) and chose to facilitate the model estimation assuming the terms of trade to be another exogenous driver (shock) with the added advantage that the interpretation of terms of trade effects is then straightforward. ${ }^{12}$ We, therefore, add a law of motion for the growth rate of

\footnotetext{
${ }^{11}$ To evaluate the fit of the three different policy rules, we will compare the marginal data density (or posterior probabilities) for the corresponding models. This will help us examine the role of the natural interest rate in monetary policy decisions in the six estimated small open-economy countries.

12 Treating the terms of trade as an exogenous driver (shock) ensure that the small open economy hypothesis holds-the domestic conditions of the small open-economy have no significant influence on neither the global economy nor on international relative prices (terms of trade, real exchange rate.)
} 
the terms of trade, $\Delta q_{t}$, to the system in the following form:

$$
\Delta q_{t}=\rho_{q} \Delta q_{t-1}+\varepsilon_{q, t}
$$

in order to close the model. We also recognize that the terms of trade growth, $\Delta q_{t}$, is an observable variablewhile, for instance, foreign output growth, $\Delta y_{A, t}^{f}$, is harder-to-measure - and therefore include terms of trade growth, $\Delta q_{t}$, and changes in the nominal exchange rate, $\Delta s_{t}$, among the set of estimation variables we rely upon to pin down empirically the international spillovers modelled in this paper.

Equations (1) - (5) together with one of the policy rule specifications in (6) - (6B) and (8) form a linear rational expectations model. We assume that the domestic preference shock, $g_{t}$, the domestic cost-push shock, $u_{t}$, the domestic technology growth shock, $z_{t}$, the terms of trade first-difference shock, $\Delta q_{t}$, the domestic monetary policy shock, $\varepsilon_{i, t}$, the rest-of-the-world output, $y_{A, t}^{f}$, and the rest-of-the-world inflation, $\pi_{t}^{f}$, evolve according to univariate $\operatorname{AR}(1)$ processes. The innovations of the $\operatorname{AR}(1)$ processes are denoted by $\varepsilon_{g, t}, \varepsilon_{u, t}, \varepsilon_{z, t}, \varepsilon_{q, t}, \varepsilon_{i, t}, \varepsilon_{y^{f}, t}$, and $\varepsilon_{\pi^{f}, t}$ and are assumed to be uncorrelated with each other at all leads and lags. The corresponding volatility coefficients for each of the $\operatorname{AR}(1)$ processes are denoted as $\sigma_{g}>0, \sigma_{u}>0$, $\sigma_{z}>0, \sigma_{q}>0, \sigma_{i}>0, \sigma_{y^{f}}>0$, and $\sigma_{\pi^{f}}>0$. The autoregressive coefficients are given, accordingly, by $-1<\rho_{g}<1,-1<\rho_{u}<1,-1<\rho_{z}<1,-1<\rho_{q}<1,-1<\rho_{y^{f}}<1$, and $-1<\rho_{\pi^{f}}<1$ coupled with the assumption that monetary policy shocks are purely transitory (and display no persistence of their own). ${ }^{13}$ The model is solved using the method described in Sims (2002) and estimated using standard Bayesian techniques as in Schorfheide (2013).

\section{Empirical Estimation Strategy}

We proceed with a discussion of our econometric methodology which is reliant on standard Bayesian techniques. We then describe the construction of the data sets that are used for the empirical work and present our choice of prior distributions for the Bayesian analysis.

\subsection{Methodology}

The focus of our empirical exercise is to estimate the distribution of the natural interest rates and explore how the rest-of-world output shock contributes to domestic natural interest rates by estimating the structural model described in Section 3. In addition, we are interested in evaluating the role of trade opennesssomething for which our framework is well suited. We also investigate whether central banks in the six small open economies track their domestic natural rate when making monetary policy decisions by comparing models with competing policy rules, i.e., the $T$ rule formulated in equation (6); the $W$ rule described in equation (6A); and the $W \& T$ rule expressed in equation $(6 B)$. To achieve the goals described above, we estimate for all countries six alternative models associated with open $(\alpha \geq 0)$ and closed $(\alpha=0)$ economy specifications under the three different monetary policy rules. ${ }^{14}$

\footnotetext{
${ }^{13}$ Persistence arises intrinsically (or endogenously) to the central bank via the smoothing parameter $0<\rho_{i}<1$. For a discussion of intrinsic inertia in contrast with extrinsic or exogenous inertia that would arise from persistence in the monetary policy shocks, see Rudebusch (2006).

${ }^{14}$ The log-linearized equilibrium conditions that describe the dynamics of our model reduce to their closed-economy counterparts when the openness parameter, $\alpha$, is set to zero.
} 
In our empirical analysis, the vector of observables, $Y_{t}$, will be composed of the output growth, the CPI inflation rate (quarter-over-quarter), the annualized nominal short-term interest rate, the depreciation rate of the domestic currency (based on the nominal narrow effective exchange rate), and terms of trade changes. All data is demeaned over the full sample. The vector of observations is related to the model variables according to:

$$
Y_{t}=\left[\Delta y_{A, t}+\frac{\tau+\tau \varphi}{1+\tau \varphi} z_{t}, \pi_{t}, 4 i_{t}, \Delta s_{t}, \Delta q_{t}\right]^{T}
$$

Recall that the foreign output variable, $y_{A, t}$, is defined as the ratio of output over the power transform of domestic aggregate productivity $A_{t}^{\frac{\tau+\tau \varphi}{1+\tau \varphi}}$. Hence, observed output growth corresponds to $\Delta y_{A, t}$ adjusted by scaled productivity growth $\frac{\tau+\tau \varphi}{1+\tau \varphi} z_{t}$. We construct the likelihood using the Kalman filter based on the statespace representation of the linear rational expectations solution of each model under consideration, setting to zero the prior probability of the configurations of values of the parameter space that imply indeterminacy. ${ }^{15}$

We estimate the model with Bayesian Markov Chain Monte Carlo (MCMC) approach which has merits in at least three aspects. First, Bayesian approach allows us to incorporate prior information which might relieve potential weak-identification problems that usually occur to DSGE models. Second, adopting Bayesian approach facilitates evaluating the uncertainty associated with the natural interest rate estimates by its posterior distribution, which is essential for monetary policy risk management as noted in Evans et al. (2016). ${ }^{16}$ Third, Bayesian method enables us to evaluate the fit of different models by computing the marginal data densities (or posterior probability) of the corresponding models using the modified harmonic mean estimator proposed by Geweke (1999). This is beneficial in comparing open-economy and closedeconomy model specifications and deciding which policy rule is more supported by the data.

When implementing the MCMC procedure, an optimization algorithm is used to obtain an initial estimate of the mode. We start the maximization algorithm from 20 different random starting values before launching the MCMC chains and check that the optimization routine always converges to the same value. This is a useful diagnostic for the presence of identification problems, conditional on a given set of priors. Indeed, our experience is that this is crucial to identify local modes which may achieve almost identical values of the posterior with sometimes rather different configurations of coefficients. Having ensured a unique mode for the baseline model, the Hessian matrix from the optimization routine is used as a proposal density, properly scaled to yield a target acceptance rate between $20 \%$ and 30\%. For the MCMC results, four chains of 250, 000 draws each were initialized by randomly selecting starting values (using an over-dispersed normal density centered at the mode with a scaled-up Hessian as variance covariance matrix). For each chain, following a burn-in phase of 62, 500 draws, convergence is monitored using the trace plots, the R-statistic of Gelman and Rubin (1992), and the SPM test of Geweke (1992).

\footnotetext{
${ }^{15}$ We also implemented an additional estimation in an environment that allows for indeterminacy in the solution with the technique of Bianchi and Nicolò (2017). However, in that exercise, the evidence continued to favor a joint distribution that puts most of its mass on the determinacy region. Results on these additional exercises are available from the authors upon request.

${ }^{16}$ Our objective is not only to obtain point estimates for the parameters of the DSGE model specified in the previous section, but also to provide accurate measures of uncertainty surrounding these estimates. Therefore, using Bayesian methods, we aim to characterize the posterior distribution of the model parameters. Given a prior, the posterior density is proportional to the product of the likelihood and the prior. As described by Schorfheide (2013), posterior draws for this density can be generated using a random-walk metropolis algorithm and the state-space representation implied by the solution of the linear rational expectations model and the Kalman filter. Measures of location and scatter are obtained from the draws by computing, for instance, the median and standard deviations as well as posterior probability bands. Furthermore, given the draws, it is possible to characterize the posterior distribution of any functional of interest by computing the corresponding functional for each of the draws. This property will later be exploited to analyze the implications of model uncertainty on optimal policy.
} 
To compare the fit across models, we calculate Kass and Raftery (1995) ratios (henceforth, KR ratios), defined as two times the log of the Bayes factor, as in Cúrdia et al. (2015). The Bayes factor of one model against another is defined as the ratio of their marginal likelihoods. Kass and Raftery (1995) recommend this measure of relative fit as its scale the same as that of a class Likelihood Ratio statistic. They suggest that values of KR above 10 can be considered "very strong" evidence in favor of a model. Values between 6 and 10 represent "strong" evidence, between 2 and 6 "positive" evidence, while values below 2 are "not worth more than a bare mention."

\subsection{Data Description}

We apply our estimation technique to six typical small open economies from four different continents, Australia, Canada, South Korea, Sweden, Switzerland, and the U.K., with quarterly data from $1983 Q 1$ to 2018Q1. All of these countries are market economies and exhibit a high degree of economic and financial integration with the rest of the world so that domestic business fluctuations are likely to have a substantial international component. ${ }^{17}$ Similar to Lubik and Schorfheide (2007), we use observations on real output growth, inflation, nominal interest rates, exchange rate changes, and terms of trade growth in our empirical analysis. All series are demeaned prior to estimation.

Output growth rates are computed as log first differences of the real GDP from the OECD Quarterly National Accounts (OECDNAQ) database and scaled by 100 to convert them into quarter-to-quarter percentages. Inflation rates are defined as log first differences (scaled by 100) of the core CPI excluding food and energy indices from the OECD Main Economic Indicators (OECDMEI) database. We calculate the depreciation rate by taking log first differences (scaled by 100) of the Bank of International Settlements (BIS) nominal narrow effective exchange rate measured by the geometric trade weighted averages of bilateral exchange rates. Apart from Sweden, the terms of trade series are measured by the ratio between the export prices of goods and services index and the corresponding import price index from OECDNAQ. The import and export prices of Sweden are from the International Monetary Fund's International Financial Statistics (IFS) database given that the relevant OECDNAQ indices only start from 1993 and are highly correlated with the respective IFS data. We take log first differences (scaled by 100) to convert the terms of trade series into their growth rates.

Consistent with Wynne and Zhang (2018b), the policy rate is proxied by the official cash rate for Australia from the Reserve Bank of Australia (G10 database), the central bank rate for Canada from the OECD Main Economic Indicators (OECDMEI database), the central bank discount rate for South Korea from the International Monetary Fund's IFS (IFS database), the overnight money rate for Sweden from the OECD Main Economic Indicators (OECDMEI database), the central bank policy rate for Switzerland from the International Monetary Fund's IFS (IFS database), and the official bank rate for the U.K. from the Bank of England (G10 database). All of the series are obtained from Haver Analytics, where the Haver mnemonics are listed in the Data Appendix to facilitate replication of our results.

\footnotetext{
${ }^{17}$ A recent paper by Fernández et al. (2015) classifies the degree of openness/closedness of the capital account of different countries as being either "open," having some controls that amount to a "gate," or having many controls that amount to a "wall." According to their measure, Canada, Sweden, and the U.K. are considered "open" countries while Australia, South Korea, and Switzerland are "gate" countries. Moreover, Grossman et al. (2014) explore the degree of openness/closedness based on data for the trade over GDP ratio concluding that South Korea, Sweden, Switzerland, and Canada have traditionally been relatively more open to trade than Australia and the U.K.- a pattern consistent with what we observe in our own data.
} 


\subsection{Choice of Priors}

Table 1 and Table 2 report our selection of priors for all the structural parameters of the reference model and the parameters that characterize the dynamics of the exogenous shock processes. Apart from the degree of openness parameter, $\alpha$, the priors for the parameters are shared for all countries across different models. To evaluate the interdependence between the small open economies and the rest of the world, in Table 2, we set country-specific prior for the openness parameter, $\alpha$, tightly centered around the average import share of the corresponding country over our sample period from $1983 Q 1$ to $2018 Q 1$.

Similar to Justiniano and Preston (2010), we impose fairly loose Gamma priors, with large tails, for the inverse Frisch elasticity of labor supply, $\varphi$, considering the diverse estimates emerging from macro and micro studies. The elasticity of substitution between home and foreign goods, $\eta$, imposes a Gamma prior centered at 1 which corresponds to the special case of perfect substitution. In our monetary policy rule, the prior on the smoothing parameter, $\rho_{i}$, has a Beta prior with dispersion wide enough to encompass most existing estimates. The Gamma priors for the feedback coefficients on inflation, $\psi_{\pi}$, and the output gap, $\psi_{x}$, are centered around the original Taylor (1993) values of 1.5 and 0.5 , respectively.

The prior distributions for the other structural parameters of the reference model are consistent with those used by Lubik and Schorfheide (2007). ${ }^{18}$ To be specific, the steady state of the annualized real interest rate adopts a Gamma distribution with a large standard deviation so that the discount factor, $\beta \equiv \exp \left(-\frac{r^{s s}}{400}\right)$, is distributed around 0.994 implying an annualized real rate of interest in steady state, $r^{s s}$, centered around a $2.5 \%$ annualized rate. The prior for the slope coefficient in the Phillips curve, $\kappa \equiv \frac{(1-\beta \theta)(1-\theta)}{\theta}$, is set with a loose Gamma prior centered at 0.5 , which is consistent with values reported elsewhere in the literature (Rotemberg and Woodford (1998); Galí and Gertler (1999); Sbordone (2002)). We also restrict the intertemporal elasticity of substitution $\tau$ to lie inside the interval $[0,1)$ with a Beta prior with a mean of 0.5 - this is consistent with the range of plausible micro and macro estimates of the intertemporal elasticity of substitution found in the literature as surveyed in Havránek (2015) and Thimme $(2017) \cdot{ }^{19}$

We then specify the same priors for the rest-of-world shocks, $y_{A, t}^{f}$, as in Lubik and Schorfheide (2007), which are set according to a pre-sample analysis using data from $1970 Q 1$ to $1982 Q 4$. The priors for the parameters of the rest-of-world output shock process are set by averaging the estimates of AR(1) models for the ratio of the U.S. GDP to domestic GDP. Similarly, the priors for parameters of the rest-of-world inflation shock, $\pi_{t}^{f}$, are obtained by fitting an AR(1) process to the U.S. CPI inflation series. Lubik and Schorfheide (2007) adopt country-specific priors for the domestic technology growth shock, $z_{t}$, and the terms of trade shock, $\Delta q_{t}$, by estimating $\mathrm{AR}(1)$ models of the output growth and the terms of trade growth in individual

\footnotetext{
${ }^{18}$ Our model setup is similar to, but more general than, Lubik and Schorfheide (2007). Instead of setting the inverse Frisch parameter and the substitution elasticity between home and foreign goods to 1, we estimate these two parameters. In addition, we also deviate from Lubik and Schorfheide (2007) by adding a cost-push shock to the Phillips curve to capture the inflation dynamics and a preference shock as an additional contributor to the natural interest rate movement. We also concentrate on different monetary policy rules than Lubik and Schorfheide (2007).

${ }^{19}$ The intertemporal elasticity of substitution $\tau$ estimated here corresponds to the inverse of the coefficient of relative risk aversion (a description of the preference specification we adopted can be found in the Appendix). Hence, the range $[0,1)$ on $\tau$ implies that the coefficient of relative risk aversion is bounded below by one (i.e., $\frac{1}{\tau}>1$ ). And, indeed, this range of values for $\frac{1}{\tau}$ is also a fairly standard characterization of the space of plausible values for the relative risk aversion. Finally, we should point out that by estimating $\tau$ in this way we relax the often-used assumption of log-utility on consumption $(\tau=1)$. Log-utility reduces the number of structural parameters to be estimated at the expense of imposing a stronger and more restrictive value for $\tau$ that appears largely inconsistent with much of the existing micro and macro empirical evidence (Havránek (2015), Thimme (2017)).
} 
countries, respectively. Given that they impose loose priors with roughly the same mean for these two shocks across countries, we select the same prior for all of the six countries by adopting their priors for the U.K. (a Beta prior for the persistence and an Inverse Gamma prior for the volatility, accordingly).

We consider a domestic preference shock, $g_{t}$, and a domestic cost-push shock, $u_{t}$, both unobserved, unlike Lubik and Schorfheide (2007). With the prior belief that the domestic households' preference does not shift substantially over our sample period, we center the priors of the persistence parameter of the preference shock, $\rho_{g}$, at 0.2 , and locate the standard deviation of the preference shock, $\sigma_{g}$, around $0.25 .{ }^{20}$ Finally, we set the priors for the cost-push shock, $u_{t}$, by adopting the same priors as for the foreign inflation shock. Specifically, our Beta prior for the persistence of the cost-push shock, $\rho_{u}$, is centered at 0.8 , and its standard deviation, $\sigma_{u}$, comes from an Inverse Gamma distribution set around 0.55.

As can be seen in the natural interest rate equation (3), the variation in the natural interest rate is only attributable to the preference shock, the technology shock and the rest-of-world output shock. Note that our priors do not imply the foreign output shock, $y_{A, t}^{f}$, has to play a dominant role in the fluctuations of the natural interest rate. For instance, when calibrating all the parameters as the prior mean for South Korea with the openness parameter $\alpha=0.30$, only around $9.70 \%$ of the volatility in the natural interest rate is attributable to the foreign output shock at short horizons which increases to $35.17 \%$ at infinite horizon. On the contrary, the contribution of the domestic technology growth shock, $z_{t}$, and the preference shock, $g_{t}$, to the natural interest rate movements is, respectively, $66.51 \%$ and $23.80 \%$ at short horizons, while $47.74 \%$ and $17.08 \%$ at an infinite horizon. The foreign output shock, $y_{A, t}^{f}$, contributes an even smaller share of the natural interest rate fluctuations in the other five countries, as South Korea is by far the country with the highest estimate import share $\alpha$ as reported in Table 2 among the small open economies in our sample.

\section{$5 \quad$ Empirical Findings}

Our structural model imposes the cross-equation restrictions arising from the small open economy framework of Gali and Monacelli (2005) and Lubik and Schorfheide (2007). We bring theory to bear in order to help us with identification - in particular, to estimate the natural rate of interest and recover its domestic and foreign drivers. In that vein, our main empirical findings in this paper aim to assess three important dimensions of the question:

First, we assess the significance of the cross-equation restrictions to fit the data by comparing our benchmark model against more parsimonious, alternative specifications that abstract from the key features of the model (notably, the international linkages that arise through trade among these small open-economies and the implementation of monetary policy in relation to the short-term natural rate of interest).

Second, we assess the estimates of the structural parameters of the model and the recovered natural rate of interest under the benchmark specification that is most consistent with the data.

Third, we report our estimates of the natural rate for the six economies, and compare them to the (real) policy rate in each country over the sample period.

Fourth, we show that foreign drivers are the dominant force explaining the fluctuations of the natural rate of interest for the economies we investigate. Moreover, we also establish that the natural rates of interest

\footnotetext{
${ }^{20}$ If the prior mean of $\rho_{g}$ is higher or with greater uncertainty, there could be convergence (bimodal) problems in the estimation with the MCMC algorithm for some of the countries in our sample. Our numerical optimization routine will have difficulties finding the maximum of the posterior density.
} 
strongly comove with the available natural rate of interest estimates for the U.S. This is consistent with the view that international spillovers have played a major role in the decline of the natural rate over the past 15 years or so.

\subsection{Model Comparison}

We begin by fitting our DSGE model to the data of all of the six small open economies. We evaluate the fit between open $(\alpha>0)$ and closed $(\alpha=0)$ specifications of the model under all three different policy rules. Figure 1 displays the KR illustrating such comparisons with bar graphs. The red bars compare the small open economy model when monetary policy is assumed to follow the conventional Taylor (1993)-type rule (the $T$ rule) against the closed-economy version of the same model with the same monetary policy rule (i.e., the case where $\alpha=0$ and the central bank implements the $T$ rule). The yellow bars show a similar model comparison between the small open economy and closed-economy specifications whenever monetary policy is assumed to follow the Wicksellian rule (the $W$ rule), while the blue bars repeat the exercise with monetary policy assumed to follow a Taylor (1993)-type rule that tracks the short-term natural rate rather than the long-term (or steady state) natural rate of the $T$ rule (the $W \& T$ rule). ${ }^{21}$ For all six countries across all three monetary policy rules, the KR ratios far exceed 10. For Australia, Canada, South Korea, and the U.K., the KR ratios are even above 30. This indicates "very strong" evidence that the small open economy specification fits the data better than the closed economy counterpart for these countries, even at the expense of introducing more parameters into the estimation. ${ }^{22}$

In the spirit of Cúrdia et al. (2015), we also evaluate whether the central banks in all six countries track the domestic (short-term) natural rate when making monetary policy. Table 3 summarizes our key findings when comparing the performance of the benchmark small open economy model under alternative specifications. Each panel shows the log-marginal likelihood (ML) for the relevant small open economy model under the $W \& T$ rule, and the KR ratio for the other models relative to the reference model (the small open economy specification with the $W \& T$ rule). Since our previous exercise showed that the open economy framework fits the data better across all the monetary rules, we focus on comparing the monetary policy rules under the small open economy model (column "KR (Open)"), although the comparison under the closed economy setup leads to similar implications for policy (column "KR (Closed)"). Given that all the numbers in the column "KR (Open)" are negative, the results show that the structural model with the $W \& T$ rule fits the data better than the same model under either the $W$ rule or the $T$ rule.

When comparing the $W \& T$ rule and the $T$ rule, we find that there is at least "positive" evidence in favor of the model featuring the $W \& T$ rule ("very strong" for Canada and Switzerland (KR > 10) while "positive" $(2<\mathrm{KR}<6)$ for Australia, Canada, South Korea, and the U.K.) This suggests that the central banks of these six countries indeed have tracked the short-term natural interest rate when making monetary policy decisions. In other words, the evidence presented here suggests that in practice the conduct of monetary policy in all six small open economies is aimed at tracking the short-term natural rate rather than the long-term (steadystate) of the original Taylor (1993) rule. This is consistent with the optimal policy implementation for small

\footnotetext{
${ }^{21}$ The $W$ rule can be viewed as a special case of the $W \& T$ rule where monetary policy tracks the Wicksellian rate but responds to deviations of domestic inflation from its target but not to the output gap.

${ }^{22}$ Martínez-García and Wynne (2014) show that Bayesian model comparison strongly penalizes overfitting which can lead us to favor a less parameterized model against the true data-generating process when the two become arbitrarily close to each other. Hence, the evidence here in favor of the small open economy model is particularly strong.
} 
open economies discussed in Clarida et al. (2001) and Gali and Monacelli (2005), among others.

Furthermore, the model with the $W \& T$ rule also fits the data better than its counterpart with the $W$ rule. When comparing the goodness of fit between the $W \& T$ rule and the $W$ rule there is at least "strong" evidence $(\mathrm{KR}>6)$ in favor of the model associated with the $W \& T$ rule, except for Canada. The KR ratio for Canada, similar to that reported in the closed economy study for the U.S. by Cúrdia et al. (2015), equals 1.9 which indicates an insignificant difference in model fitness according to the criteria in Kass and Raftery (1995). This indicates that central banks in most of the countries respond to inflation deviations as well as to the output gap when making monetary policy decisions. As a result, in the remainder of the paper, we will focus on the results from the model estimates with the $W \& T$ rule and under the small open economy assumption, which allows the monetary policy to track the short-term natural interest rate and at the same time respond to both inflation and the output gap. ${ }^{23}$

\subsection{Parameter Estimates}

The Bayesian estimates of the structural parameters of the model for all six countries can be found in Table 4 . In addition to $90 \%$ posterior probability intervals, we report posterior means as point estimates. The results are by and large consistent with the literature. The posterior mean of the degree of openness, $\alpha$, ranges from 0.12 for the U.K. to 0.30 for the South Korea. For all six countries, $\alpha$ is significantly above 0 (and statistically different from it), which conforms with our previous results on model comparison suggesting that it is better to estimate the natural rate for these countries using an open economy framework. The estimates of all other structural parameters also fall within plausible ranges.

There is also a reasonably high degree of interest rate smoothing by the central banks in all six countries, with the estimate of $\rho_{i}$ ranging from 0.53 for Australia to 0.75 for the U.K. We find that countries such as Switzerland, Canada, and the U.K. pursue a slightly more anti-inflationary policy - with posterior means for $\psi_{\pi}$ around 1.90 - than countries such as Australia, South Korea, and Sweden-where the posterior means for $\psi_{\pi}$ are all around 1.40. The estimates of the parameters of the monetary policy rule in all six countries lie comfortably within the determinacy region over our sample period. ${ }^{24}$ The central bank of Switzerland is more responsive to the output gap, with $\psi_{x}$ close to 0.70 , than other countries, where estimates of $\psi_{x}$ range between 0.38 and 0.55 . Our estimates of $\psi_{\pi}$ for Australia are very close to the estimates reported by Lubik and Schorfheide (2007) - 1.38 versus their estimate of 1.41. For the U.K., we obtain an estimate of 1.83, somewhat bigger than their estimate of 1.30, while for Canada we obtain an estimate of 1.95, not too different from their estimate of 1.84 under their alternative prior. Although the posterior means for the monetary policy parameters $\left(\psi_{\pi}, \psi_{x}\right.$, and $\left.\rho_{i}\right)$ for all countries do not differ markedly from their priors, the data appear informative as the posterior distributions for the policy parameters are more concentrated than the prior distributions.

The range of estimates of the elasticity of intertemporal substitution, $\tau$, goes from 0.26 to 0.73 , which is within the range of other estimates of this parameter from previous micro and macro studies as surveyed in Havránek (2015) and Thimme (2017). ${ }^{25}$ Our estimates of $\varphi$ range between 1.53 (Switzerland) and 3.07 (South

\footnotetext{
${ }^{23}$ The estimation results for other specifications are available upon request.

${ }^{24}$ This is robust even when we estimate our preferred model specification allowing for indeterminacy with the technique of Bianchi and Nicolò (2017).

${ }^{25}$ Lubik and Schorfheide (2007) estimate values for $\tau$ for Canada of 0.31 and 0.29 depending on their choice of priors, somewhat smaller than our estimate of 0.44 but well-within the range of values for $\tau$ that are consistent with the bulk of the empirical evidence (Havránek (2015), Thimme (2017)).
} 
Korea), implying Frisch elasticity estimates of between 0.33 and 0.65 , which is close to the range of estimates employed by the U.S. Congressional Budget Office (CBO) to assess the effects of tax policy (see Reichling and Whalen (2012)). This range of estimates is more in keeping with the values reported elsewhere in the micro literature (usually between 0 and 0.5 ) than with the values commonly used to calibrate general equilibrium macro models. ${ }^{26}$ Our estimates of the elasticity of substitution between domestic and foreign goods, $\eta$, range between 0.63 and 1.22. These estimates are somewhat lower than the range of "macroelasticity" estimates reported by Feenstra et al. (2018) (which range from 1.2 to 4.1). Gallaway et al. (2003) report a range of short-term Armington elasticities at the detailed industry level between 0.15 and 4.85, with an average estimate of 0.95 , and a range of long-term elasticities of 0.52 to 4.83 , with an average of 1.55 . Blonigen and Wilson (1999) report an average Armington elasticity of 0.81.

All of our estimates of the slope of the Phillips curve, $\kappa$, within the Gali and Monacelli (2005) model appear positive and statistically significant - ranging from 0.38 (the U.K.) to 1.87 (South Korea). ${ }^{27}$ Our point estimates of the slope of the Phillips curve, $\kappa$, are largely consistent with the estimates reported by other authors based on a range of techniques (see, e.g., the values estimated by Lubik and Schorfheide (2007) for Canada, those of Holmberg (2006) for Sweden, and the estimated values of Abbas et al. (2016) for Australia). ${ }^{28}$

The estimates of the parameters of the stochastic processes for the shocks capture the substantial degree of persistence found in the data, most of which comes from the persistence of the stationarized foreign output shock ( $\rho_{y^{f}}>0.89$ for all countries) and the cost-push shock $\left(\rho_{u}>0.92\right.$ for all countries). The preference shock exhibits more moderate persistence, with estimates for $\rho_{g}$ ranging between 0.24 and 0.51 . The domestic technology growth shock exhibit even less persistence, with $\rho_{z}<0.07$. This implies that the persistence that is found in the output growth rates for the small open economies we look at is mostly propagated from foreign countries, which is consistent with the hypothesis of "catch-up effects" discussed in Benhabib and Tonetti (2014).

Figure 2 shows the impulse responses and the associated $90 \%$ confidence band of the natural interest rates to their potential contributors for all the six countries. The signs of all the impulse responses are consistent with the implications of equation (3). The technology growth shock causes a rise in the natural interest rate. The foreign output shock and the preference shock are assumed to be stationary and generated by an exogenously-given AR(1) stochastic process. As a result, positive level shocks in preferences and foreign output can be considered as negative growth rate shocks and, thus, reduce the natural rate of interest. The technology growth shock causes a transitory increase in the natural interest rate. The magnitude of the response of the U.K. natural interest rate is larger than the response for the other countries. The impact effects of the preference shock and the foreign output shock are greater, while the response to the foreign output shock exhibits more persistence.

\footnotetext{
${ }^{26}$ See Chetty et al. (2011), Keane and Rogerson (2012), and Peterman (2016) for a discussion of how to reconcile the micro and macro estimates.

${ }^{27}$ We considered an alternative choice of priors to discipline $\kappa \equiv \frac{(1-\beta \theta)(1-\theta)}{\theta}$ which involves calibrating $\beta$ at its mean and placing a prior directly on $\theta$. However, the estimated results on $\kappa$ under this alternative choice of priors are largely the same (and available upon request).

${ }^{28}$ Compared with the findings of Lubik and Schorfheide (2007) whose approach is closest to ours, our estimate of the slope of Phillips Curve, $\kappa$, for Canada of 0.65 is somewhat larger than theirs (which is reported to be between 0.29 and 0.32 depending on their choice of prior).
} 


\subsection{Natural Rate Estimates}

Figure 3 shows time series of our estimates of the natural rates of interest for the six countries we look at around their implicit historical means. We illustrate the estimates based on both small open-economy (blue solid line) and closed economy (green dashed line) model specifications. We assume that monetary policy follows the $W \& T$ rule $(6 B)$ in the closed-economy case as it does for the reference small-open economy model. To facilitate the assessment of the stance of monetary policy we also include the demeaned real policy rate for each country, computed as the nominal policy rate less inflation over the previous four quarters in deviations from its historical mean (black solid line). The $90 \%$ posterior probability bands associated with the small estimates of the natural rate for the reference are plotted in the blue shaded area. These confidence bands generally are tighter than those estimated with semi-structural models (e.g., Holston et al. (2017) and Fries et al. (2018)) as we use more of the cross-equation restrictions that arise from theory.

The wedge between the natural rate estimate of the reference small open-economy model and its closedeconomy counterpart illustrates the substantial bias that arises in our view of the natural rate whenever the estimated model is misspecified by ignoring the strong trade linkages that influence the dynamics of the domestic economy (imposing that $\alpha=0$ ). On the one hand, the cases of Australia, South Korea, and Sweden in Figure 3 show how misspecification of the degree of openness $\alpha$ can distort the natural rate of interest recovered from the model and affect our inferences about the stance of monetary policy. Moreover, the misspecified closed-economy estimates of the natural rate of interest for those three countries would lead us conclude that their respective domestic natural rates have been largely insulated from the pattern of decline seen among many of the major advanced economies while the small-open economy estimates favored by the data strongly indicate the opposite is true.

On the other hand, even when the discrepancy between the closed-economy and small open-economy estimates of the natural rate is less pronounced - as is the case for the other three countries: Canada, Switzerland, and the U.K.- the closed-economy specification may distort our inferences about the natural rate in other ways. For starters, it tends to magnify the decline of the natural rate of interest that we document through the lens of the reference small open-economy model for Canada, Switzerland, and the U.K. Furthermore, the observed fall of the natural rate under the misspecified closed-economy model would be attributed entirely to domestic factors while the reference small open-economy model tells us otherwise.

In short, the evidence presented here shows that under a misspecified closed-economy specification, we would erroneously infer that the domestic natural rate of these six countries has been more resilient and largely immune to the natural rate drops seen among major advanced economies-underscoring the importance of taking account of the openness of these economies when making empirical inferences about their natural rate of interest.

The estimated natural rates follow the same broad downward trend over the past thirty five years in all six countries, and all fall significantly below their implicit mean around the year 2000, with the fall being most pronounced in the aftermath of the Global Financial Crisis of 2007-2009. The extent to which the real policy rate tracks the estimates of the natural rate varies substantially across countries. Central banks in Australia, Canada, and the U.K. seem to track the small open-economy estimates of the natural rate reasonably closely, while for South Korea, Sweden, and Switzerland we find episodes where the real policy rate deviates by a noticeable amount from our reference estimates of the natural rate. Moreover, we also find that monetary policy has been generally loose for all six countries in the aftermath of the Global 
Financial Recession of 2007-2009 - given the observation that the real interest rate appears well below the small open-economy estimate of the natural interest rate.

By the end of our sample in 2018Q1, our reference estimates in Figure 3 indicate that monetary policy remains quite accommodative in Canada, Sweden, and Switzerland with an implied real interest rate gap close to $1 \%$ while monetary policy returned to a more neutral stance for the other three countries in our dataset (Australia, South Korea, and the U.K.). However, the misspecified closed-economy estimates of the natural rate would lead us to a rather different interpretation of the current monetary policy stance in all six countries. In particular, if we take the degree of openness, $\alpha$, to be zero, the closed-economy models point out that monetary policy is rather loose for Australia, South Korea, and Sweden as of $2018 Q 1$ (the end of our sample) with an interest rate gap close to $-3.5 \%$ for Australia, $-0.8 \%$ for South Korea, and $-2 \%$ for Sweden. The small open-economy estimates, in turn, indicate a more neutral monetary stance for the remaining countries, with an interest rate gap less than $-0.5 \%$ for Australia, $0 \%$ for South Korea, and $-1 \%$ for Sweden. These significant differences, again, highlight the importance of estimating with a structural framework the natural rate of interest and henceforth the stance of monetary policy by explicitly incorporating the international linkages of the economy to the rest of the world.

Figure 4 shows the history of (demeaned) nominal policy rates in the six countries and illustrates its pattern of comovement, while Figure 5 shows on a comparable scale the estimated natural rates recovered under the reference model (a small open economy under the $W \& T$ rule). Figure 5 suggests that the recent history of natural rates can be divided into three distinct episodes. From the early 1980s through the mid1990s, natural rates were generally higher (relative to their respective means) in all six countries. From the mid-1990s through 2007 or so, rates hovered around their means. And from 2008 up until most recently, natural rates have been negative in all six countries to a greater or lesser extent. Figure 5 also shows the significant impact of the Global Financial Crisis of 2007-2009 on the recovered natural rates of interest as well as the subsequent downward shift of the natural rates over time. Moreover, we also should note that the steep decline in the natural rate seen on these six economies is quite sticky and does not appear to show signs of mean-reversion by the end of our sample in 2018Q1.

\subsection{Foreign Spillovers}

In many (mostly-advanced) economies, there has been a declining trend in interest rates over the past 35 years. Since the financial crisis, interest rates have remained particularly low. Though a decrease in inflation explains part of the fall in nominal interest rates, there is also a clear downward trend in real interest rates among many leading advanced economies (e.g., Holston et al. (2017) and Fries et al. (2018)). Our findings suggest similar patterns for small open economies where the real rate declines appear to track declines in the natural rate of interest. In here, we document the strong comovement between the natural rates of interest in all six small open economies in our sample. In turn, we also show that the stance of monetary policy defined simply as the deviation between the real rate and the natural rate is only weakly correlated across these small open economies.

We follow the suggestion of David (1949) to compute a single summary statistic of the degree of co-

movement of the natural rates in the six countries. With six countries there are $C_{6}^{2}=15$ simple pairwise correlations between natural rate estimates. If we let $\operatorname{corr}_{k}$ denote the simple pairwise correlation between 
country $i$ and country $j, i, j=1, \ldots, 6$ and $i \neq j$, then the proposed summary measure is given by:

$$
\operatorname{corr}=\tanh \left(\frac{\sum_{k=1}^{15} T_{k} \tanh ^{-1}\left(\operatorname{corr}_{k}\right)}{\sum_{i=k}^{15} T_{k}}\right)
$$

where tanh $(\cdot)$ is the standard hyperbolic tangent function and $T_{k}$ is the sample size for the $k$-th correlation $\operatorname{corr}_{k}$. The aggregate correlation between nominal interest rates in the six countries we consider is 0.87 , while the aggregate correlation between our estimates of natural rates is 0.84 . However, the aggregate correlation between the interest rate gaps (i.e., the difference between the real rate and the natural rate) is only 0.18 . This is also apparent from Figure 6, where we plot the time series of the interest rate gaps over our sample period. The quantitative measure in (9) confirms the strong comovement among natural rates of interest in all six small open economies in our sample that is apparent by simple visual inspection-and similarly confirms the weak correlation for the stance of monetary policy.

We also calculate the correlation between our natural rate estimates and estimates of the natural rate for the U.S. Rather than take a stand on a specific natural rate series for the U.S., we compute an average correlation with five different U.S. series (those of Laubach and Williams (2003), Kiley (2015), Lubik and Matthes (2015), Holston et al. (2017), and Johannsen and Mertens (2018)). ${ }^{29}$ The results are shown in Table 5. Our natural rate estimates are highly correlated with similar estimates for the U.S., suggesting a high degree of international spillovers and an important role for foreign shocks as drivers of the natural rate in the open economies we look at.

Against this backdrop, a debate has emerged over the factors that might have contributed to the worldwide decline in natural rates. Our findings suggest that the dynamics of domestic natural interest rate in small open economies are largely driven by foreign factors and strongly correlated with similar patterns of decline in the U.S. and elsewhere (as suggested by the evidence reported in Table 5). This is consistent with the view that international spillovers are playing a significant role among smaller economies whose domestic fundamentals may not necessarily have weakened. In order to dig deeper into this, we report the results of a variance decomposition exercise with our reference model (a small open-economy model with the $W \& T$ rule) in Table 6.

We decompose fluctuations of our estimates of the short-term natural rate of interest in each of the six countries into the components attributable to technology shocks, preference shocks, and foreign output shocks at horizons of one quarter, eight quarters (two years), twenty quarters (five years), as well as at an infinite horizon. We see that at an infinite horizon, the foreign output shock accounts for well over half of the variation in the natural rate, and about $85 \%$ in Australia and Canada. Even on impact, foreign output shocks are important, especially for Australia, Canada, and the U.K. The evidence presented here, therefore, is consistent with the broad implications of the rest of our findings that strongly suggest that openness plays a major role in the economy and introduces a link between foreign developments and the behavior of the domestic natural rate of interest.

This variance decomposition exercise shows more than comovement; it clearly shows that foreign shocks

\footnotetext{
${ }^{29}$ The U.S. natural rate estimated by Laubach and Williams (2003) is obtained from https://www.frbsf.org/economicresearch/files/Laubach_Williams_updated_estimates.xlsx; the estimates of Holston et al. (2017) are from https://www.frbsf.org/economic-research/files/Holston_Laubach_Williams_estimates.xlsx; and those of Lubik and Matthes (2015) are available at https://www.richmondfed.org/püblications/research/economic_brief/2015/eb_15-10. The U.S. natural rates of interests estimated by Kiley (2015) and Johannsen and Mertens (2018) were obtained directly from the authors upon request - we thank them for sharing their data with us.
} 
are a major factor driving the domestic natural rates of these six small open economies. But to what extent is this result truly informative? Our choice of priors could play a critical role here-however, the setup of the small open-economy model under the $W \& T$ rule (which tracks the short-term natural rate) that we take as our reference model for its empirical performance (goodness-of-fit) does not necessarily imply that foreign shocks ought to play a large role driving the natural rate of interest. We performed a similar variance decomposition exercise under our priors and we found that the contribution of foreign shocks to the natural rate of interest is a lot smaller than what is reported in Table 6 under the posterior estimates. ${ }^{30}$ This indicates, not just that our findings are informative about the role of foreign shocks, but most notably that foreign spillovers do play a major role - in fact, a dominant role - on the domestic natural rate.

This, coupled with the evidence presented earlier, paints a very distinct picture about the natural rate of interest in small open economies. It suggests that domestic factors and, in particular, a perceived domestic productivity slowdown are not necessarily what lies behind the declining natural rates in these small open economies. The totality of our findings point straight at spillovers from the rest of the world as the dominant factor behind the observed decline. And this, needless to say, has major implications for monetary policy which through the natural rate becomes very dependent on developments abroad (over which it has no influence) even when domestic economic conditions have remained largely unchanged. In plain English, one could say that natural rates in major advanced economies can be the result of weakening long-term prospects but they can be powerful enough to drag with them the natural rates (and monetary policy) on countries that are otherwise not subject to the same domestic malaïse.

\section{Concluding Remarks}

This paper provides new estimates of the natural rate of interest for six small open economies and quantifies the relative importance of domestic versus foreign factors in driving fluctuations in the natural rate over the past three and a half decades. We use the small open economy framework of Gali and Monacelli (2005) and Lubik and Schorfheide (2007), generalized to allow for exogenous technological progress and a more flexible representation of preferences (including shocks to preferences). To begin, we assess the significance of the cross-equation restrictions to fit the data by comparing our benchmark model against more parsimonious, alternative specifications that abstract from the key features of the model (the international linkages that arise through trade and the implementation of monetary policy). From this evidence, we conclude that there is strong evidence in favor of the small open economy specification and the assumption that policymakers' aim is to track the short-term (rather than the long-term) natural rate of interest when implementing monetary policy.

Taking the setup favored by the data as our reference model, we find robust evidence that the natural rates have been trending down in all six countries over time. We also show that they also tend to comove strongly with each other and with natural rate estimates for the U.S., consistent with our empirical evidence of significant international spillovers and a large role for foreign output shocks in driving the natural rate of interest among small open economies. Indeed, our variance decomposition exercise finds that foreign output shocks account for between $60 \%$ and $85 \%$ of the movement in natural rates at infinite horizons. Hence, we provide supportive evidence to show that foreign drivers are the dominant force explaining the fluctuations

\footnotetext{
${ }^{30}$ These results are available from the authors upon request.
} 
of the natural rate of interest for the six small open economies we investigate here. We therefore conclude that international spillovers are one very important propagation channel that has contributed to drag natural interest rates in these economies rather than domestic forces. In other words, contagion from major advanced economies appears to be the key factor at play.

The analysis in this paper could usefully be extended along a number of dimensions. To begin with, the framework of Gali and Monacelli (2005) which forms the basis for our analysis abstracts from potentially important dimensions of globalization, such as trade in intermediate inputs that are used in production. Rumler (2007) and Leith and Malley (2007) show how the small open economy can be extended to incorporate such trade. Second, we followed Lubik and Schorfheide (2007) in assuming that the terms of trade follows an exogenous stochastic process, which simplifies model estimation but violates the spirit of general equilibrium analysis. And finally, allowing for capital accumulation would greatly enrich the dynamics of the model and potentially sharpen our insights into the drivers of the natural rate. We leave those avenues open for future research. 


\section{References}

Abbas, S., P. Bhattacharya, D. Mallick, and P. Sgro (2016). The New Keynesian Phillips Curve in a Small Open Economy: Empirical Evidence from Australia. Economic Record 92(298), 409-434. https://doi.org/10.1111/1475-4932.12262.

Andrade, P., J. Galí, H. Le Bihan, and J. Matheron (2018). The Optimal Inflation Target and the Natural Rate of Interest. Technical report, National Bureau of Economic Research No. 24328. https://doi.org/10.3386/w24328.

Andrés, J., J. D. López-Salido, and E. Nelson (2009). Money and the Natural Rate of Interest: Structural Estimates for the United States and the Euro Area. Journal of Economic Dynamics and Control 33(3), 758-776. https://doi.org/10.1016/j.jedc.2008.01.011.

Armelius, H., M. Solberger, and E. Spånberg (2018). Is the Swedish Neutral Interest Rate Affected by International Developments? Sveriges Riksbank Economic Review 1, 22-37. https://goo.gl/E44euB.

Barsky, R., A. Justiniano, and L. Melosi (2014). The Natural Rate of Interest and Its Usefulness for Monetary Policy. American Economic Review 104(5), 37-43. https://doi.org/10.1257/aer.104.5.37.

Benhabib, J., P. J. and C. Tonetti (2014). Catch-up and Fall-back Through Innovation and Imitation. Journal of Economic Growth 19(1), 1-35. https://doi.org/10.1007/s10887-013-9095-z.

Berger, T. and B. Kempa (2014). Time-Varying Equilibrium Rates in Small Open Economies: Evidence for Canada. Journal of Macroeconomics 39, 203-214. https://doi.org/10.1016/j.jmacro.2013.12.002.

Bernanke, B. S. (2015a). Why Are Interest Rates So Low? Brookings Institution, Blog Post, March 30, 2015. https://goo.gl/kjrAzN.

Bernanke, B. S. (2015b). Why Are Interest Rates So Low, Part 2: Secular Stagnation. Brookings Institution, Blog Post, March 31, 2015. https://goo.gl/mYat3D.

Bernanke, B. S. (2015c). Why Are Interest Rates So Low, Part 3: The Global Savings Glut. Brookings Institution, Blog Post, April 1, 2015. https://goo.gl/cRpQmo.

Bernanke, B. S. (2015d). Why Are Interest Rates So Low, Part 4: Term Premiums. Brookings Institution, Blog Post, April 13, 2015. https://goo.gl/CcUVpF.

Bianchi, F. and G. Nicolò (2017). A Generalized Approach to Indeterminacy in Linear Rational Expectations Models. National Bureau of Economic Research Working Papers no. 23521. https://doi.org/10.3386/w23521.

Blonigen, B. A. and W. W. Wilson (1999). Explaining Armington: What Determines Substitutability Between Home and Foreign Goods? The Canadian Journal of Economics 32(1), 1-21. https://doi.org/10.2307/136392.

Borio, C., P. Disyatat, M. Juselius, and P. Rungcharoenkitkul (2017). Why So Low For So Long? A Long-Term View of Real Interest Rates. BIS Working Papers 685, Bank for International Settlements. https://www.bis.org/publ/work685.htm.

Calvo, G. A. (1983). Staggered Prices in a Utility-Maximizing Framework. Journal of Monetary Economics 12(3), 383-398. https://doi.org/10.1016/0304-3932(83)90060-0. 
Chetty, R., A. Guren, D. Manoli, and A. Weber (2011). Are Micro and Macro Labor Supply Elasticities Consistent? A Review of Evidence on the Intensive and Extensive Margins. American Economic Review Papers and Proceedings 101(3), 471-475. https://doi.org/10.1257/aer.101.3.471.

Clarida, R., J. Galí, and M. Gertler (2001). Optimal Monetary Policy in Open Versus Closed Economies: An Integrated Approach. American Economic Review, Papers and Proceedings 91(2), 248-252. https://doi.org/10.1257/aer.91.2.248.

Clarida, R. H. (2017). The Global Factor in Neutral Policy Rates: Some Implications for Exchange Rates, Monetary Policy, and Policy Coordination. NBER Working Paper No. 23562. https://doi.org/10.3386/w23562.

Clark, T. E. and S. Kozicki (2005). Estimating Equilibrium Real Interest Rates in Real Time. The North American Journal of Economics and Finance 16(3), 395-413. https://doi.org/10.1016/j.najef.2005.04.002.

Coibion, O. and Y. Gorodnichenko (2015). Is the Phillips Curve Alive and Well after All? Inflation Expectations and the Missing Disinflation. American Economic Journal: Macroeconomics 7(1), 197232. https://doi.org/10.1257/mac.20130306.

Cúrdia, V., A. Ferrero, G. C. Ng, and A. Tambalotti (2015). Has U.S. Monetary Policy Tracked the Efficient Interest Rate? Journal of Monetary Economics 70, 72-83. https://doi.org/10.1016/j.jmoneco.2014.09.004.

David, F. N. (1949). The Moments of the $\mathrm{z}$ and F Distributions. Biometrika 36(3/4), 394-403. https://doi.org/10.2307/2332676.

Del Negro, M., D. Giannone, M. P. Giannoni, and A. Tambalotti (2017). Safety, Liquidity, and the Natural Rate of Interest. Brookings Papers on Economic Activity 2017(1), 235-316. https://doi.org/10.1353/eca.2017.0003.

Del Negro, M., D. Giannone, M. P. Giannoni, and A. Tambalotti (2018). Global Trends in Interest Rates. NBER Working Paper No. 25039. https://doi.org/10.3386/w25039.

Eggertsson, G. B., N. R. Mehrotra, and J. A. Robbins (2017). A Model of Secular Stagnation: Theory and Quantitative Evaluation. National Bureau of Economic Research No. 23093. https://doi.org/10.3386/w23093.

Evans, C., J. Fisher, F. Gourio, and S. Krane (2016). Risk Management for Monetary Policy Near the Zero Lower Bound. Brookings Papers on Economic Activity 2015(1), 141-219. https://doi.org/10.1353/eca.2016.0003.

Feenstra, R. C., P. Luck, M. Obstfeld, and K. Russ (2018). In Search of the Armington Elasticity. The Review of Economics and Statistics 100(1), 135-150. https://doi.org/10.1162/rest_a_00696.

Fernández, A., M. W. Klein, A. Rebucci, M. Schindler, and M. Uribe (2015). Capital Control Measures: A New Dataset. National Bureau of Economic Research No. 20970. https://doi.org/10.3386/w20970.

Fiorentini, G., A. Galesi, G. Pérez-Quirós, and E. Sentana (2018). The Rise and Fall of the Natural Interest Rate. Banco de Espana Working Paper No. 1822. https://goo.gl/bwuoDf. 
Fries, S., J.-S. Mésonnier, S. Mouabbi, and J.-P. Renne (2018). National Natural Rates of Interest and the Single Monetary Policy in the Euro Area. Journal of Applied Econometrics 33(6), 763-779. https://doi.org/10.1002/jae.2637.

Gagnon, E., B. K. Johannsen, and D. Lopez-Salido (2016). Understanding the New Normal: The Role of Demographics. Finance and Economics Discussion Series 2016-080. https://doi.org/10.17016/feds.2016.080.

Gali, J. and T. Monacelli (2005). Monetary Policy and Exchange Rate Volatility in a Small Open Economy. The Review of Economic Studies 72(3), 707-734. https://doi.org/10.1111/j.1467-937x.2005.00349.x.

Gallaway, M. P., C. A. McDaniel, and S. A. Rivera (2003). Short-Run and Long-Run Industry-Level Estimates of U.S. Armington Elasticities. North American Journal of Economics and Finance 14(1), 49-68. https://doi.org/10.1016/s1062-9408(02)00101-8.

Galí, J. and M. Gertler (1999). Inflation Dynamics: A Structural Econometric Analysis. Journal of Monetary Economics 44(2), 195-222. https://doi.org/10.1016/s0304-3932(99)00023-9.

Gelman, A. and D. B. Rubin (1992). Inference From Iterative Simulation Using Multiple Sequences. Statistical Science 7(4), 457-472. https://doi.org/10.1214/ss/1177011136.

Geweke, J. (1992). Evaluating the Accuracy of Sampling-Based Approaches to the Calculations of Posterior Moments. Bayesian Statistics 4, 641-649.

Geweke, J. (1999). Using Simulation Methods for Bayesian Econometric Models: Inference, Development, and Communication. Econometric Reviews 18(1), 1-73. https://doi.org/10.1080/07474939908800433.

Grossman, V., A. Mack, and E. Martínez-García (2014). A New Database of Global Economic Indicators. The Journal of Economic and Social Measurement 39(3), 163-197. https://www.doi.org/10.3233/JEM-140391.

Hamilton, J. D., E. S. Harris, J. Hatzius, and K. D. West (2016). The Equilibrium Real Funds Rate: Past, Present, and Future. IMF Economic Review 64(4), 660-707. https://doi.org/10.1057/s41308016-0015-z.

Havránek, T. (2015). Measuring Intertemporal Substitution: The Importance of Method Choice and Selective Reporting. Journal of the European Economic Association 13(6), 1180-1204. https://doi.org/10.1111/jeea.12133.

Hirose, Y. and T. Sunakawa (2017). The Natural Rate of Interest in a Nonlinear DSGE Model. CAMA Working Papers 2017-38. Centre for Applied Macroeconomic Analysis (CAMA), Crawford School of Public Policy, The Australian National University. https://doi.org/10.2139/ssrn.2967137.

Holmberg, K. (2006). Derivation and Estimation of a New Keynesian Phillips Curve in a Small Open Economy. Sveriges Riksbank Working Paper No. 197. https://doi.org/10.2139/ssrn.985902.

Holston, K., T. Laubach, and J. C. Williams (2017). Measuring the Natural Rate of Interest: International Trends and Determinants. Journal of International Economics 108, S59-S75. https://doi.org/10.1016/j.jinteco.2017.01.004.

Hristov, A. (2016). Measuring the Natural Rate of Interest in the Eurozone: A DSGE Perspective. In CESifo Forum, Volume 17, pp. 86-91. München: Ifo Institut-Leibniz Institut für Wirtschaftsforschung an der Universität München. https://www.cesifo-group.de/DocDL/forum-2016-1-hristov-march.pdf. 
Johannsen, B. K. and E. Mertens (2018). A Time Series Model of Interest Rates with the Effective Lower Bound. BIS Working Papers 715, Bank for International Settlements. https://www.bis.org/publ/work715.htm.

Juselius, M., C. Borio, P. Disyatat, and M. Drehmannb (2017). Monetary Policy, the Financial Cycle, and Ultra-Low Interest Rates. International Journal of Central Banking 13(3), 55-89. https://www.ijcb.org/journal/ijcb17q3a2.pdf.

Justiniano, A. and B. Preston (2010). Monetary Policy and Uncertainty in an Empirical Small OpenEconomy Model. Journal of Applied Econometrics 25(1), 93-128. https://doi.org/10.1002/jae.1153.

Kara, E. and L. von Thadden (2016). Interest Rate Effects of Demographic Changes in a New Keynesian Life-Cycle Framework. Macroeconomic Dynamics 20(1), 120-164. https://doi.org/10.1017/s1365100514000273.

Kass, R. E. and A. E. Raftery (1995). Bayes Factors. Journal of the American Statistical Association 90(430), 773-795. https://doi.org/10.1080/01621459.1995.10476572.

Keane, M. and R. Rogerson (2012). Micro and Macro Labor Supply Elasticities: A Reassessment of Conventional Wisdom. Journal of Economic Literature 50(2), 464-476. https://doi.org/10.1257/jel.50.2.464.

Kiley, M. T. (2015). What Can the Data Tell Us About the Equilibrium Real Interest Rate? Finance and Economics Discussion Series 2015-077. https://doi.org/10.17016/feds.2015.077.

Laubach, T. and J. C. Williams (2003). Measuring the Natural Rate of Interest. Review of Economics and Statistics 85(4), 1063-1070. https://doi.org/10.1162/003465303772815934.

Leith, C. and J. Malley (2007). Estimated Open Economy New Keynesian Phillips Curves for the G7. Open Economies Review 18(4), 405-426. https://doi.org/10.1007/s11079-007-9008-x.

Lubik, T. A. and C. Matthes (2015). Calculating the Natural Rate of Interest: A Comparison of Two Alternative Approaches. Richmond Fed Economic Brief (Oct.), 1-6. https://goo.gl/ngg94o.

Lubik, T. A. and F. Schorfheide (2007). Do Central Banks Respond to Exchange Rate Movements? A Structural Investigation. Journal of Monetary Economics 54(4), 1069-1087. https://doi.org/10.1016/j.jmoneco.2006.01.009.

Martínez-García, E. (2015). The Global Content of Local Inflation: Revisiting the Empirical Content of the Global Slack Hypothesis. In W. Barnett and F. Jawadi (Eds.), Monetary Policy in the Context of the Financial Crisis: New Challenges and Lessons, pp. 51-112. Emerald Group Publishing Limited. https://doi.org/10.1108/s1571-038620150000024016.

Martínez-García, E. (2017). Good Policies or Good Luck? New Insights on Globalization and the International Monetary Policy Transmission Mechanism. Computational Economics, 1-36, September 15, 2017. https://doi.org/10.1007/s10614-017-9746-9.

Martínez-García, E. and M. A. Wynne (2010). The Global Slack Hypothesis. Federal Reserve Bank of Dallas Staff Papers, 10. September. https://goo.gl/uqSXM1.

Martínez-García, E. and M. A. Wynne (2014). Assessing Bayesian Model Comparison in Small Samples. Advances in Econometrics 34, 71-115. Bayesian Model Comparison (Advances in Econometrics, Volume 34). https://doi.org/10.1108/s0731-905320140000034006. 
Mavroeidis, S., M. Plagborg-Møller, and J. H. Stock (2014). Empirical Evidence on Inflation Expectations in the New Keynesian Phillips Curve. Journal of Economic Literature 52(1), 124-188. https://doi.org/10.1257/jel.52.1.124.

Mesonnier, J.-S. and J.-P. Renne (2007). A Time-Varying "Natural" Rate of Interest for the Euro Area. European Economic Review 51(7), 1768-1784. https://doi.org/10.1016/j.euroecorev.2006.11.006.

Nelson, E. (2002). Direct Effects of Base Money on Aggregate Demand: Theory and Evidence. Journal of Monetary Economics 49(4), 687-708. https://doi.org/10.1016/s0304-3932(02)00118-6.

Neri, S. and A. Gerali (2018). Natural Rates Across the Atlantic. Journal of Macroeconomics. Available online 24 April 2018. https://doi.org/10.1016/j.jmacro.2018.04.007.

Neto, A. R. and O. Candido (2018). Measuring the Neutral Real Interest Rate in Brazil: A SemiStructural Open Economy Framework. Empirical Economics, 1-17. First Online: 05 September 2018. https://doi.org/10.1007/s00181-018-1550-4.

Pescatori, A. and J. Turunen (2015). Lower for Longer: Neutral Rates in the United States. IMF Working Paper WP/2015/135. https://doi.org/10.5089/9781513508382.001.

Peterman, W. B. (2016). Reconciling Micro and Macro Estimates of the Frisch Labor Supply Elasticity. Economic Inquiry 54(1), 100-120. https://doi.org/10.1111/ecin.12252.

Powell, J. H. (2018). Monetary Policy in a Changing Economy. Remarks at "Changing Market Structure and Implications for Monetary Policy," a symposium sponsored by the Federal Reserve Bank of Kansas City. Jackson Hole, Wyoming. https://goo.gl/K8n2VZ.

Reichling, F. and C. Whalen (2012). Review of Estimates of the Frisch Elasticity of Labor Supply. Congressional Budget Office (CBO) Working Paper 2012-13. https://www.cbo.gov/publication/43676.

Rotemberg, J. J. and M. Woodford (1998). An Optimization-Based Econometric Model for the Evaluation of Monetary Policy. In B. S. Bernanke and J. J. Rotemberg (Eds.), NBER Macroeconomics Annual 1997, vol. 12, Volume 12, pp. 297-346. Cambridge, Massachusetts, USA: MIT University Press. https://doi.org/10.2307/3585236.

Rudebusch, G. D. (2006). Monetary Policy Inertia: Fact or Fiction? International Journal of Central Banking 2(4), 85-135. https://www.ijcb.org/journal/ijcb06q4a4.htm.

Rumler, F. (2007). Estimates of the Open Economy New Keynesian Phillips Curve for Euro Area Countries. Open Economies Review 18(4), 427-451. September. https://doi.org/10.1007/s11079-007-9028-6.

Sbordone, A. M. (2002). Prices and Unit Labor Costs: A New Test of Price Stickiness. Journal of Monetary Economics 49(2), 265-292. https://doi.org/10.1016/s0304-3932(01)00111-8.

Schorfheide, F. (2013). Estimation and Evaluation of DSGE Models: Progress and Challenges. In D. Acemoglu, M. Arellano, and E. Dekel (Eds.), Advances in Economics and Econometrics. Tenth World Congress, Volume Volume 3, Econometrics, pp. 184-230. Cambridge University Press. https://doi.org/10.1017/cbo9781139060035.006.

Sims, C. A. (2002). Solving Linear Rational Expectations Models. Computational Economics 20(1), 1-20. https://doi.org/10.1023/A:1020517101123. 
Taylor, J. B. (1993). Discretion versus Policy Rules in Practice. Carnegie-Rochester Conference Series on Public Policy 39, 195-214. https://doi.org/10.1016/0167-2231(93)90009-l.

Thimme, J. (2017). Intertemporal Substitution in Consumption: A Literature Review. Journal of Economic Surveys 31(1), 226-257. https://doi.org/10.1111/joes.12142.

Trehan, B. and T. Wu (2007). Time-Varying Equilibrium Real Rates and Monetary Policy Analysis. Journal of Economic Dynamics and Control 31(5), 1584-1609. https://doi.org/10.1016/j.jedc.2006.04.009.

Wicksell, K. (1898). Interest and Prices. Translated by R.F. Kahn (1936).

Williams, J. C. (2017). Three Questions on R-star. FRBSF Economic Letter 2017-05. https://goo.gl/kp9jf3.

Woodford, M. (2003). Interest and Prices. Foundations of a Theory of Monetary Policy. Princeton, New Jersey: Princeton University Press.

Wynne, M. A. and R. Zhang (2018a). Estimating the Natural Rate of Interest in an Open Economy. Empirical Economics 55(3), 1291-1318. https://doi.org/10.1007/s00181-017-1315-5.

Wynne, M. A. and R. Zhang (2018b). Measuring the World Natural Rate of Interest. Economic Inquiry 56(1), 530-544. https://doi.org/10.1111/ecin.12500. 


\section{Appendix}

\section{A Appendix: Small Open-Economy Model}

Our benchmark model discussed in Section 3 is a variant of the standard small open-economy model described in Gali and Monacelli (2005) and Lubik and Schorfheide (2007). We deviate from these two papers by adding a cost-push shock to the Phillips curve to better capture the dynamics of inflation and a preference shock as an additional contributor to variation in the natural interest rate. We also consider different specifications of monetary policy rules from these two papers. Different from Gali and Monacelli (2005), we assume a non-stationary technology to properly account for economic growth and maintain a flexible representation of business cycles. Our model setup is more general than Lubik and Schorfheide (2007) who also apply a Bayesian approach to estimate a small open-economy model with (exogenous) domestic technological growth. However, instead of setting the inverse Frisch parameter to 0 and the substitution elasticity between home and foreign goods equal to 1 as they did, we estimate these two parameters. Here we present the key derivations of the benchmark model.

\section{A.1 Households}

Each household in the home country solves the following optimization problem:

$$
\mathbb{E}_{0} \sum_{t=0}^{\infty} \beta^{t} e^{-g_{t}}\left[\frac{C_{t}^{1-\frac{1}{\tau}}}{1-\frac{1}{\tau}}-\frac{N_{t}^{1+\varphi}}{1+\varphi}\right]
$$

subject to the following period budget constraint:

$$
P_{t} C_{t}+\mathbb{E}_{t}\left(\Lambda_{t, t+1} D_{t+1}\right) \leqslant W_{t} N_{t}+D_{t}+T_{t}+P r_{t},
$$

where $C_{t}$ is a composite consumption index defined as $C_{t} \equiv\left[(1-\alpha)^{\frac{1}{\eta}}\left(C_{H, t}\right)^{\frac{\eta-1}{\eta}}+\alpha^{\frac{1}{\eta}}\left(C_{F, t}\right)^{\frac{\eta-1}{\eta}}\right]^{\frac{\eta}{\eta-1}}, C_{H, t}$ is the sub-index of domestic goods consumption given by $C_{H, t} \equiv \int_{0}^{1} C_{H, t}(j)^{\frac{\epsilon-1}{\epsilon}} d j, C_{F, t}$ is an analogous subindex of consumption of imported goods given by $C_{F, t} \equiv \int_{0}^{1} C_{F, t}\left(j^{*}\right)^{\frac{\epsilon-1}{\epsilon}} d j^{*}$, and $N_{t}$ denotes hours worked. Furthermore, $P_{t}$ is the price level on the bundle of consumption goods $C_{t}, W_{t}$ denotes the nominal wage rate, $\mathrm{Pr}_{t}$ denotes the profits (or losses) accrued from full ownership of the domestic firms (final goods producers and intermediate goods producers), $T_{t}$ is a lump-sum tax raised by the government of the Home country, ${ }^{31}$ $D_{t}$ refers to the domestic households' holdings of Arrow-Debreu securities spanning over all possible domestic and foreign events of nature, and $\Lambda_{t, t+1}$ is the state-contingent price of these Arrow-Debreu securities.

The parameter $\tau>0$ denotes the intertemporal elasticity of substitution, $\varphi>0$ represents the inverse of the Frisch elasticity of labor supply, $\alpha$ measures the degree of openness (the import share in the consumption basket), $\epsilon>1$ is the elasticity of substitution between varieties produced within each country, and $\eta>0$ measures the substitutability between Home and Foreign goods from the viewpoint of the domestic consumer.

The aggregate preference shock $g_{t}$ shifts the intertemporal allocation of consumption without affecting

\footnotetext{
${ }^{31} T_{t}$ is generally thought as supporting a labor employment subsidy scheme that cancels out in steady state the monopolistic competition markup charged by intermediate goods producers.
} 
the intratemporal margin between leisure and consumption. It follows a stationary AR(1) process given by:

$$
g_{t}=\rho_{g} g_{t-1}+\varepsilon_{t}^{g}
$$

Solving the domestic household's optimization problem above leads to the following first-order conditions (a labor supply equation and an Euler equation):

$$
\begin{aligned}
C_{t}^{-\frac{1}{\tau}} W_{t} & =n_{t}^{\varphi} P_{t}, \\
C_{t}^{-\frac{1}{\tau}} e^{-g_{t}} & =\beta \mathbb{E}_{t}\left[\left(1+i_{t}\right)\left(1+\mathbb{E}_{t}\left(\pi_{t+1}\right)\right)^{-1} C_{t+1}^{-\frac{1}{\tau}} e^{-g_{t+1}}\right]
\end{aligned}
$$

where $\pi_{t}$ is the CPI inflation rate and the short-term nominal interest rate is given by $1+i_{t} \equiv \frac{1}{\mathbb{E}_{t}\left(\Lambda_{t, t+1}\right)}$ (where $\mathbb{E}_{t}\left(\Lambda_{t, t+s}\right)=\beta^{s} \mathbb{E}_{t}\left[e^{-g_{t+s}}\left(\frac{C_{t+s}}{C_{t}}\right)^{-\frac{1}{\tau}} \frac{P_{t}}{P_{t+s}}\right]$ for any $s \geq 1$ ).

\section{A.2 Firms}

\section{A.2.1 Final Goods Firms}

Final goods firms in the Home country produce output with a continuum of intermediate goods according to a constant elasticity of substitution (CES) technology. The $j$-th domestic firm chooses its production, $Y_{t}(j)$, to maximize per period profits, i.e., to maximize:

$$
P_{H, t}\left(\int_{0}^{1} Y_{t}(j)^{\frac{\epsilon-1}{\epsilon}} d j\right)^{\frac{\epsilon}{\epsilon-1}}-\int_{0}^{1} P_{H, t}(j) Y_{t}(j) d j
$$

taking the individual domestic produced goods price of variety $j, P_{H, t}(j)$, as given. Solving the final goods firms' optimization problem, we obtain the intermediate goods demand function:

$$
Y_{t}(j)=\left(\frac{P_{H, t}(j)}{P_{H, t}}\right)^{-\epsilon} Y_{t}
$$

where $Y_{t} \equiv\left(\int_{0}^{1} Y_{t}(j)^{\frac{\epsilon-1}{\epsilon}} d j\right)^{\frac{\epsilon}{\epsilon-1}}$ measures the total production of the final goods in the home country, and $P_{H, t} \equiv\left(\int_{0}^{1} P_{H, t}(j)^{1-\epsilon} d j\right)^{\frac{1}{1-\epsilon}}$ is the price sub-index of domestically produced goods. Equation (16) indicates that the relative demand for the $j$-th intermediate good is a function of its relative price, with $\epsilon$ the price elasticity of demand, and is proportional to aggregate output, $Y_{t}$.

\section{A.2.2 Intermediate Goods Firms}

A typical intermediate goods firm in the home economy produces a differentiated good (one of the domestic varieties) with a linear-in-labor technology represented by the production function:

$$
Y_{t}(j)=A_{t} N_{t}(j)
$$

where $A_{t}$ measures the aggregate TFP productivity (or, to be precise, the aggregate labor productivity) and $N_{t}(j)$ denotes the labor employed by the $j$-th firm (the firm producing good variety $j$ ). We assume that 
aggregate productivity, $A_{t}$, grows at a rate, $z_{t} \equiv \ln \left(\frac{A_{t}}{A_{t-1}}\right)$, and that the exogenous growth rate displays some persistence:

$$
z_{t}=\rho_{z} z_{t-1}+\varepsilon_{z, t}
$$

The real marginal cost, $M C_{t}$, is defined as:

$$
M C_{t} \equiv \frac{W_{t}}{P_{H, t} A_{t}}
$$

The intermediate goods firms set prices on a staggered basis as in Calvo (1983) where $\theta$ is the probability a firm keeps its price fixed in a given period. We assume that the firms pay a tax at the rate $\nu_{t}$. This tax is introduced so as cancel out the monopolistic competition (markup) distortion in steady state. Firms that are able to choose their price optimally in period $t$ choose the reset price $P_{t}(j)$ to maximize their expected present value of future profits:

$$
\mathbb{E}_{t} \sum_{s=0}^{\infty} \theta^{s} \Lambda_{t, t+s}\left[\left(1-\nu_{t+s}\right) P_{H, t+s}(j) Y_{t+s \mid t}(j)-M C_{t+s} P_{H, t+s}\left(Y_{t+s \mid t}(j)\right)\right],
$$

subject to:

$$
\begin{aligned}
Y_{t+s}(j) & =\left(\frac{P_{H, t+s}(j)}{P_{H, t+s}}\right)^{-\epsilon} Y_{t+s}, \\
\Lambda_{t, t+s} & \equiv \beta^{s} \mathbb{E}_{t}\left[e^{-g_{t+s}} \frac{\lambda_{t+s}}{\lambda_{t}} \frac{P_{t}}{P_{t+s}}\right],
\end{aligned}
$$

and the real marginal cost given in (19). Solving this problem, we have:

$$
\begin{aligned}
1+\pi_{H, t}^{\#} & =\frac{\epsilon}{\epsilon-1}\left(1+\pi_{H, t}\right) \frac{\zeta_{1 t}}{\zeta_{2 t}} \\
\zeta_{1 t} & \equiv C_{t}^{-\frac{1}{\tau}} M C_{t} Y_{t}+\alpha \beta \mathbb{E}_{t}\left[e^{-\Delta g_{t+1}}\left(1+\pi_{H, t+1}\right)^{\theta} \zeta_{1, t+1}\right] \\
\zeta_{2 t} & \equiv C_{t}^{-\frac{1}{\tau}}\left(1-\nu_{t}\right) Y_{t}+\alpha \beta \mathbb{E}_{t}\left[e^{-\Delta g_{t+1}}\left(1+\pi_{H, t+1}\right)^{\theta-1} \zeta_{2, t+1}\right]
\end{aligned}
$$

where $\pi_{H, t}^{\#}=\frac{P_{H, t}^{\#}}{P_{H, t}}-1$ is the reset price inflation rate with $P_{H, t}^{\#}$ denoting the optimal price set by the updating firms. Again by Calvo (1983) price setting, the law of large numbers implies that the domestic price inflation $\pi_{H, t} \equiv \frac{P_{H, t}}{P_{H, t-1}}-1$ evolves according to:

$$
\left(1+\pi_{H, t}\right)^{1-\theta}=(1-\alpha)\left(1+\pi_{H, t}^{\#}\right)^{1-\theta}
$$

\section{A.3 Market Clearing Condition}

The goods market clearing condition is given by:

$$
Y_{t}=C_{H, t}+C_{H, t}^{f},
$$


where $C_{H, t}^{f}$ is the foreign country's consumption of home country produced goods. The optimal demand functions for $C_{H, t}$ and $C_{H, t}^{f}$ are formalized as:

$$
\begin{aligned}
C_{H, t} & =(1-\alpha)\left(\frac{P_{H, t}}{P_{t}}\right)^{-\eta} C_{t}, \\
C_{H, t}^{f} & =\alpha\left(\frac{S_{t} P_{H, t}}{P_{t}^{f}}\right)^{-\eta} C_{t}^{f},
\end{aligned}
$$

where $S_{t}$ denotes the nominal exchange rate. The foreign country is assumed to be a nearly closed economy so that $C_{t}^{f} \simeq Y_{t}^{f}$.

\section{A.4 Stationarize the Model}

Given that domestic aggregate productivity is assumed to contain a stochastic trend, we stationarize the model by defining $Y_{A, t} \equiv \frac{Y_{t}}{A_{t}^{\frac{\tau+\tau \varphi}{1+\tau \varphi}}}, C_{A, t} \equiv \frac{C_{t}}{A_{t}^{\frac{\tau+\tau \varphi}{1+\tau \varphi}}}, Y_{A, t}^{f} \equiv \frac{Y_{t}^{f}}{A_{t}^{\frac{\tau+\tau \varphi}{1+\tau \varphi}}}, N_{A, t} \equiv \frac{N_{t}}{A_{t}^{\frac{\tau-1}{1+\tau \varphi}}}$, and $W_{A, t} \equiv \frac{W_{t}}{A_{t}}$. We then transform the first-order conditions arising from the domestic household optimization problem ((13) and (14)) as follows:

$$
\begin{aligned}
C_{A, t}^{-\frac{1}{\tau}} W_{A, t} & =N_{A, t}^{\varphi} P_{t}, \\
C_{A, t}^{-\frac{1}{\tau}} e^{-g_{t}} & =\beta \mathbb{E}_{t}\left[\left(1+i_{t}\right)\left(1+\mathbb{E}_{t}\left(\pi_{t+1}\right)\right)^{-1} C_{A, t+1}^{-\frac{1}{\tau}} e^{-g_{t+1}} e^{-\left(\frac{1+\varphi}{1+\tau \varphi}\right) z_{t+1}}\right] .
\end{aligned}
$$

The real marginal cost equation (19) becomes:

$$
M C_{t} \equiv \frac{W_{A, t}}{P_{H, t}}
$$

Let us define $\zeta_{1 A, t} \equiv \zeta_{1 t} A_{t}^{-\frac{(\tau-1)(1+\varphi)}{1+\tau \varphi}}$ and $\zeta_{2 A, t} \equiv \zeta_{2 t} A_{t}^{-\frac{(\tau-1)(1+\varphi)}{1+\tau \varphi}}$, then we can transform equations (23), (24), and (25) in the following form:

$$
\begin{aligned}
1+\pi_{H, t}^{\#} & =\frac{\epsilon}{\epsilon-1}\left(1+\pi_{H, t}\right) \frac{\zeta_{1 A, t}}{\zeta_{2 A, t}} \\
\zeta_{1 A, t} & =C_{A, t}^{-\frac{1}{\tau}} M C_{t} Y_{A, t}+\theta \beta \mathbb{E}_{t}\left[e^{-\Delta g_{t+1}+\left(\frac{(\tau-1)(1+\varphi)}{1+\tau \varphi}\right) z_{t+1}}\left(1+\pi_{t+1}\right)^{\epsilon} \zeta_{1 A, t+1}\right], \\
\zeta_{2 A, t} & =C_{A, t}^{-\frac{1}{\tau}}\left(1-\nu_{t}\right) Y_{A, t}+\theta \beta \mathbb{E}_{t}\left[e^{-\Delta g_{t+1}+\left(\frac{(\tau-1)(1+\varphi)}{1+\tau \varphi}\right) z_{t+1}}\left(1+\pi_{t+1}\right)^{\epsilon-1} \zeta_{2 A, t+1}\right] .
\end{aligned}
$$

Similarly, we define $C_{A H, t} \equiv \frac{C_{H, t}}{A_{t}^{\frac{\tau+\tau \varphi}{1+\tau \varphi}}}$ and $C_{A H, t}^{f} \equiv \frac{C_{H, t}^{f}}{A_{t}^{\frac{\tau+\tau \varphi}{1+\tau \varphi}}}$ in order to stationarize equations (27), (28), and (29) as follows:

$$
\begin{aligned}
Y_{A, t} & =C_{A H, t}+C_{A H, t}^{f}, \\
C_{A H, t} & =(1-\alpha)\left(\frac{P_{H, t}}{P_{t}}\right)^{-\eta} C_{A, t}, \\
C_{A H, t}^{f} & =\alpha\left(\frac{s_{t} P_{H, t}}{P_{t}^{f}}\right)^{-\eta} C_{A, t}^{f} .
\end{aligned}
$$




\section{B Appendix: Log-Linearized Equilibrium Conditions}

Unless otherwise noted, we use lower-case letters in place of capital letters in order to denote the variables in log-deviations from the steady state when log-linearizing the equilibrium conditions of the model.

\section{B.1 Terms of Trade and Perfect Risk-Sharing}

Given that $C_{t} \equiv\left[(1-\alpha)^{\frac{1}{\eta}}\left(C_{H, t}\right)^{\frac{\eta-1}{\eta}}+\alpha^{\frac{1}{\eta}}\left(C_{F, t}\right)^{\frac{\eta-1}{\eta}}\right]^{\frac{\eta}{\eta-1}}$ is a composite of both home country goods, $C_{H, t}$, and foreign country goods, $C_{F, t}$, in a CES aggregator form, the domestic inflation rate of consumption goods, $\pi_{t}$, can be expressed as a weighted average of the inflation rate of the domestically produced goods, $\pi_{H, t}$, and the inflation rate of imported goods, $\pi_{F, t}$, with the degree of openness as the weight associated with $\pi_{F, t}:$

$$
\pi_{t}=(1-\alpha) \pi_{H, t}+\alpha \pi_{F, t},
$$

If we define the $\log$ of terms of trade as $q_{t} \equiv \ln \left(\frac{P_{H, t}}{P_{F, t}}\right)$, it follows that the domestic CPI inflation rate is a function of the domestic producer price inflation and the growth rate of the terms of trade as follows:

$$
\pi_{t}=\pi_{H, t}-\alpha \Delta q_{t}
$$

Assume that the law of one price holds for all individual goods at all times (both for import and export prices), then it follows that $p_{F, t}=s_{t}+p_{t}^{f}$. Rewriting the law of one price equation in terms of growth rates and combining it with equations (39) and (40), we obtain the following expression for the growth rate of the terms of trade:

$$
\begin{aligned}
-\Delta q_{t} & =\pi_{F, t}-\pi_{H, t} \\
& =\left(\Delta s_{t}+\pi_{t}^{f}\right)-\left(\pi_{t}+\alpha \Delta q_{t}\right) \\
& =\Delta s_{t}-\pi_{t}^{f}-\pi_{t}-\alpha \Delta q_{t} .
\end{aligned}
$$

This implies that the CPI inflation rate can be formalized as a linear combination of the depreciation rate of the exchange rate, $\Delta s_{t}$, the growth rate of the terms of trade, $\Delta q_{t}$, and foreign CPI inflation, $\pi_{t}^{f}$ :

$$
\pi_{t}=\Delta s_{t}+(1-\alpha) \Delta q_{t}+\pi_{t}^{f}
$$

In addition, under the assumption of complete domestic and international asset markets (whereby the set of Arrow-Debreu securities traded internationally span all possible states of nature), there is perfect risk sharing between the home and the foreign country which implies an identical stochastic discount factor across countries and across all possible states of nature:

$$
\beta e^{-g_{t+1}}\left(\frac{C_{t+1}}{C_{t}}\right)^{-\frac{1}{\tau}} \frac{P_{t}}{P_{t+1}}=\beta e^{-g_{t+1}}\left(\frac{C_{t+1}^{f}}{C_{t}^{f}}\right)^{-\frac{1}{\tau}}\left(\frac{P_{t}^{f}}{P_{t+1}^{f}}\right)\left(\frac{S_{t}}{S_{t+1}}\right),
$$

where $S_{t}$ denotes the level of the nominal exchange rate. If we stationarize the perfect risk-sharing equation (43) and then log-linearize it around the steady state, we obtain the following risk-sharing condition in log 
terms:

$$
c_{A, t}=c_{A, t}^{f}-\tau(1-\alpha) q_{t} .
$$

\section{B.2 Market Equilibrium Condition}

If we log-linearize the equilibrium conditions (36), (37), and (38) around the steady state and substitute in the definition of the terms of trade in (41), we obtain the following equations:

$$
\begin{aligned}
y_{A, t} & =(1-\alpha) c_{A H, t}+\alpha c_{A H, t}^{f}, \\
c_{A H, t} & =-\alpha \eta q_{t}+c_{A, t}, \\
c_{A H, t}^{f} & =-\eta q_{t}+c_{A, t}^{f} .
\end{aligned}
$$

Combining the above equations, we have a stationarized and log-linearized goods market equilibrium condition of the following form:

$$
y_{A, t}=(1-\alpha) c_{A, t}+\alpha c_{A, t}^{f}-(2-\alpha) \alpha \eta q_{t} .
$$

The foreign country is considered a nearly closed economy so that $c_{A, t}^{f} \simeq y_{A, t}^{f}$. Combining this with the home country goods market equilibrium condition (48) and with the perfect risk-sharing condition (44), we have:

$$
y_{A, t}=y_{A, t}^{f}-\frac{1}{\tau_{\alpha}} q_{t}
$$

where $\tau_{\alpha} \equiv \frac{1}{\tau+\alpha(2-\alpha)(\eta-\tau)}$.

\section{B.3 The Phillips Curve}

If we log-linearize the marginal cost equation (32) and then substitute in equation (49), we obtain that:

$$
\begin{aligned}
m c_{t} & =\left(w_{A, t}-p_{t}\right)+\left(p_{t}-p_{H, t}\right) \\
& =\frac{1}{\tau} c_{A, t}+\varphi n_{A, t}-\alpha q_{t} \\
& =\frac{1}{\tau} y_{A, t}^{f}+\varphi y_{A, t}-q_{t} \\
& =\left(\tau_{\alpha}+\varphi\right) y_{A, t}+\left(\frac{1}{\tau}-\tau_{\alpha}\right) y_{A, t}^{f} .
\end{aligned}
$$

In a frictionless economy, the real marginal cost in the home country, $m c_{t}^{n}$, is formalized as:

$$
m c_{t}^{n}=\left(\tau_{\alpha}+\varphi\right) y_{A, t}^{n}+\left(\frac{1}{\tau}-\tau_{\alpha}\right) y_{A, t}^{f}
$$

Under flexible prices and perfect competition, the natural marginal cost is constant (equal to one) for all $t$ and, therefore, the $\log$ of the natural marginal cost is $m c_{t}^{n}=0$. Thus,

$$
y_{A, t}^{n}=-\Gamma_{*} y_{A, t}^{f}
$$


where $\Gamma_{*} \equiv \frac{1-\tau \tau_{\alpha}}{\tau \tau_{\alpha}+\tau \varphi}$. Log-linearizing the domestic firm's price-setting equilibrium condition yields an equation determining domestic inflation, $\pi_{H, t}$, as a function of the deviations of the real marginal cost from its natural counterpart, $m c_{t}-m c_{t}^{n}$, which can be written as:

$$
\begin{aligned}
\pi_{H, t} & =\beta \mathbb{E}_{t}\left(\pi_{H, t+1}\right)+\kappa\left(m c_{t}-m c_{t}^{n}\right) \\
& =\beta \mathbb{E}_{t}\left(\pi_{H, t+1}\right)+\kappa\left(\varphi+\tau_{\alpha}\right) x_{t},
\end{aligned}
$$

where the slope of the Phillips curve is related to the composite coefficients $\kappa \equiv \frac{(1-\beta \theta)(1-\theta)}{\theta}$ and $\tau_{\alpha} \equiv$ $\frac{1}{\tau+\alpha(2-\alpha)(\eta-\tau)}$, and the output gap is defined as $x_{t} \equiv y_{A, t}-y_{A, t}^{n}$. Substituting into (53) the condition (40), the small open economy Phillips curve for CPI inflation, $\pi_{t}$, can be expressed as:

$$
\pi_{t}=\beta \mathbb{E}_{t}\left(\pi_{t+1}\right)+\alpha \beta \mathbb{E}_{t}\left(\Delta q_{t+1}\right)-\alpha \Delta q_{t}+\left(\tau_{\alpha}+\varphi\right) \kappa x_{t}+u_{t} .
$$

\section{B.4 Dynamic IS Curve and Natural Interest Rate Equation}

If we log-linearize the Euler equation (31) around the steady state, we have:

$$
c_{A, t}=\mathbb{E}_{t}\left(c_{A, t+1}\right)-\tau\left[i_{t}-\mathbb{E}_{t}\left(\pi_{t+1}\right)-\mathbb{E}_{t}\left(\Delta g_{t+1}\right)-\frac{1+\varphi}{1+\tau \varphi} \mathbb{E}_{t}\left(z_{t+1}\right)\right] .
$$

Substituting into the Euler equation (55) the home country goods market equilibrium condition from (48) $\left(y_{A, t}=(1-\alpha) c_{A, t}+\alpha c_{A, t}^{f}-(2-\alpha) \alpha \eta q_{t}\right)$, the perfect risk-sharing condition from (49) $\left(y_{A, t}=y_{A, t}^{f}-\frac{1}{\tau_{\alpha}} q_{t}\right)$, the domestic potential output equation from (52) $\left(y_{A, t}^{n} \equiv-\Gamma_{*} y_{A, t}^{f}\right)$, and the foreign country goods market

equilibrium condition $\left(c_{A, t}^{f} \simeq y_{A, t}^{f}\right)$, we can rewrite after some algebra the small open economy IS curve in terms of the domestic output gap, $x_{t} \equiv y_{A, t}-y_{A, t}^{n}$, as follows:

$$
x_{t}=\mathbb{E}_{t}\left(x_{t+1}\right)-\frac{1}{(1-\alpha) \tau_{\alpha}}\left(i_{t}-\mathbb{E}_{t}\left(\pi_{t+1}\right)-r_{t}^{n}\right)
$$

and the domestic natural interest rate, $r_{t}^{n}$, is formalized as:

$$
r_{t}^{n}=\mathbb{E}_{t}\left(\Delta g_{t+1}\right)+\left(\frac{1+\varphi}{1+\tau \varphi}\right) \mathbb{E}_{t}\left(z_{t+1}\right)+\left[\frac{1}{\tau}-(1-\alpha) \tau_{\alpha}\left(\Gamma_{*}+1\right)\right] \mathbb{E}_{t}\left(\Delta y_{A, t+1}^{f}\right)
$$

where $\Gamma_{*} \equiv \frac{1-\tau \tau_{\alpha}}{\tau \tau_{\alpha}+\tau \varphi} \cdot 32$

\footnotetext{
${ }^{32}$ The natural interest rate equation can be expressed as: $r_{t}^{n}=\mathbb{E}_{t}\left(\Delta g_{t+1}\right)+\left[(1-\alpha) \tau_{\alpha} \Gamma_{a}+\left(\frac{\tau+\tau \varphi}{1+\tau \varphi}\right)\left(\alpha \tau_{\alpha}\left(\Gamma_{*}+1\right)+\varphi \Gamma_{*}\right)\right] \mathbb{E}_{t}\left(z_{t+1}\right)+\left[\alpha \tau_{\alpha}\left(\Gamma_{*}+1\right)+\varphi \Gamma_{*}\right] \mathbb{E}_{t}\left(\Delta y_{A t+1}^{f}\right)$, where $\Gamma_{a} \equiv \frac{1+\varphi}{\tau_{\alpha}+\varphi}$. We can verify that $(1-\alpha) \tau_{\alpha} \Gamma_{a}+\left(\frac{\tau+\tau \varphi}{1+\tau \varphi}\right)\left[\alpha \tau_{\alpha}\left(\Gamma_{*}+1\right)+\varphi \Gamma_{*}\right]=\frac{1+\varphi}{1+\tau \varphi}$ and $\alpha \tau_{\alpha}\left(\Gamma_{*}+1\right)+\varphi \Gamma_{*}=$ $\frac{1}{\tau}-(1-\alpha) \tau_{\alpha}\left(\Gamma_{*}+1\right)$. Hence, the domestic natural rate, $r_{t}^{n}$, equation above reduces to that in $(57)$.
} 


\section{Appendix: Data Sources}

Our data are all from Haver Analytics. To facilitate replication of our results, the Haver mnemonics used to construct our data set are listed as follows:

Real GDP: Australia: B193GDPC@OECDNAQ; Canada: B156GDPC@OECDNAQ; South Korea: B542GDPC@OECDNAQ; Sweden: B144GDPC@OECDNAQ; Switzerland: B146GDPC@OECDNAQ; U.K.: B112GDPC@OECDNAQ.

Core CPI: Australia: SA(C193CZCN@OECDMEI); Canada: SA(C156CZCN@OECDMEI); South Korea: SA(C542CZCN@OECDMEI); Sweden: SA(C144CZCN@OECDMEI); Switzerland: SA(C146CZCN@OECDMEI); U.K.: SA(C112CZCN@OECDMEI), where "SA" denotes the series was seasonally adjusted by Haver Analytics.

Policy Rate: Australia: N193RTAR@G10; Canada: C156FROS@OECDMEI; South Korea: C542IFC@IFS; Sweden: C144FRUO@OECDMEI; Switzerland: C146IC@IFS; U.K.: N112RTAR@G10.

Nominal Narrow Effective Exchange Rate: Australia: B193XNN@BIS; Canada: B156XNN@BIS; South Korea: B542XNN@BIS; Sweden: B144XNN@BIS; Switzerland: B146XNN@BIS; U.K.: B112XNN@BIS.

Export Price: Australia: C193XPI@OECDNAQ; Canada: C156XPI@OECDNAQ; South Korea: C542XPI@OECDNAQ; Sweden: C144CP@IFS; Switzerland: C146XPI@OECDNAQ; U.K.: C112XPI@OECDNAQ.

Import Price: Australia: C193MPI@OECDNAQ; Canada: C156MPI@OECDNAQ; South Korea: C542MPI@OECDNAQ; Sweden: C144CPX@IFS; Switzerland: C146MPI@OECDNAQ; U.K.: C112MPI@OECDNAQ.

Import Value: Australia: C193GMCP@OECDMEI; Canada: C156GMCP@OECDMEI; South Korea: C542GMCP@OECDMEI; Sweden: C144GMCP@OECDMEI; Switzerland: C146GMCP@OECDMEI; U.K.: C112GMCP@OECDMEI. 


\section{Appendix: Tables and Figures}

Table 1: Prior Distributions for Parameters

\begin{tabular}{lcccccc}
\hline \hline Name & Description & Range & Density & Mean & Std. Dev & $90 \%$ Interval \\
\hline$\varphi$ & Inverse Frisch & $\mathbb{R}^{+}$ & Gamma & 1.50 & 0.50 & {$[0.78,2.41]$} \\
$\eta$ & Elasticity H-F goods & $\mathbb{R}^{+}$ & Gamma & 1.00 & 0.20 & {$[0.70,1.35]$} \\
$\psi_{\pi}$ & Monetary rule, inflation & $\mathbb{R}^{+}$ & Gamma & 1.50 & 0.50 & {$[0.78,2.41]$} \\
$\psi_{x}$ & Monetary rule, output & $\mathbb{R}^{+}$ & Gamma & 0.50 & 0.25 & {$[0.17,0.97]$} \\
$\rho_{i}$ & Monetary rule, smoothing & {$[0,1)$} & Beta & 0.50 & 0.20 & {$[0.17,0.83]$} \\
$r^{s s}$ & Steady state real interest & $\mathbb{R}^{+}$ & Gamma & 2.50 & 1.00 & {$[1.11,4.34]$} \\
$\kappa$ & Phillips curve, slope & $\mathbb{R}^{+}$ & Gamma & 0.50 & 0.25 & {$[0.17,0.97]$} \\
$\tau$ & Inter. elast. of substitution. & {$[0,1)$} & Beta & 0.50 & 0.20 & {$[0.17,0.83]$} \\
$\rho_{q}$ & Terms of trade & {$[0,1)$} & Beta & 0.40 & 0.20 & {$[0.10,0.75]$} \\
$\rho_{z}$ & Technology & {$[0,1)$} & Beta & 0.20 & 0.10 & {$[0.06,0.39]$} \\
$\rho_{g}$ & Preference & {$[0,1)$} & Beta & 0.20 & 0.10 & {$[0.06,0.39]$} \\
$\rho_{y^{f}}$ & World output & {$[0,1)$} & Beta & 0.90 & 0.05 & {$[0.81,0.97]$} \\
$\rho_{\pi}$ & World inflation & {$[0,1)$} & Beta & 0.80 & 0.10 & {$[0.61,0.94]$} \\
$\rho_{u}$ & Cost-push shock & {$[0,1)$} & Beta & 0.80 & 0.10 & {$[0.61,0.94]$} \\
$\sigma_{i}$ & sd monetary rule & $\mathbb{R}^{+}$ & InvGamma & 0.50 & 0.20 & {$[0.29,0.86]$} \\
$\sigma_{q}$ & sd terms of trade & $\mathbb{R}^{+}$ & InvGamma & 1.50 & 0.55 & {$[0.90,2.50]$} \\
$\sigma_{z}$ & sd technology & $\mathbb{R}^{+}$ & InvGamma & 1.00 & 0.35 & {$[0.61,1.64]$} \\
$\sigma_{y}$ & sd world output & $\mathbb{R}^{+}$ & InvGamma & 1.50 & 0.35 & {$[1.05,2.15]$} \\
$\sigma_{\pi f}$ & sd world inflation & $\mathbb{R}^{+}$ & InvGamma & 0.55 & 0.20 & {$[0.33,0.92]$} \\
$\sigma_{u}$ & sd cost-push & $\mathbb{R}^{+}$ & InvGamma & 0.55 & 0.20 & {$[0.33,0.92]$} \\
$\sigma_{g}$ & sd preference & $\mathbb{R}^{+}$ & InvGamma & 0.25 & 0.10 & {$[0.14,0.43]$} \\
\hline
\end{tabular}

Note: Except for the degree of openness $\alpha$, we set identical priors for all six countries. The effective priors are truncated at the boundary of the determinacy region.

Table 2: Country-Specific Priors for the Degree of Openness $(\alpha)$

\begin{tabular}{lccccc}
\hline \hline Name & Range & Density & Mean & Std. Dev. & $90 \%$ Interval \\
\hline Australia & {$[0,1)$} & Beta & 0.15 & 0.05 & {$[0.08,0.24]$} \\
Canada & {$[0,1)$} & Beta & 0.25 & 0.05 & {$[0.17,0.34]$} \\
South Korea & {$[0,1)$} & Beta & 0.30 & 0.05 & {$[0.22,0.39]$} \\
Sweden & {$[0,1)$} & Beta & 0.27 & 0.05 & {$[0.19,0.36]$} \\
Switzerland & {$[0,1)$} & Beta & 0.27 & 0.05 & {$[0.19,0.36]$} \\
U.K. & {$[0,1)$} & Beta & 0.20 & 0.05 & {$[0.12,0.29]$} \\
\hline
\end{tabular}

Note: The prior mean of the degree of openness is set to the average of the corresponding country's average import share from 1983Q1 to 2018Q1. 
Table 3: Model Comparison

\begin{tabular}{|c|c|c|c|c|}
\hline Name & Policy Rule $\left(i_{t}^{*}\right)$ & KR (Open) & KR (Closed) & ML (W\&T, Open) \\
\hline Australia & & & & -1243.62 \\
\hline $\mathrm{W} \& \mathrm{~T}$ & $r_{t}^{n}+\psi_{\pi} \pi_{t}+\psi_{x} x_{t}$ & 0 & -38.94 & \\
\hline W & $r_{t}^{n}+\psi_{\pi} \pi_{t}$ & $-6.50^{* *}$ & -39.59 & \\
\hline $\mathrm{T}$ & $\psi_{\pi} \pi_{t}+\psi_{x} x_{t}$ & $-4.92^{*}$ & -44.34 & \\
\hline Canada & & & & -976.78 \\
\hline $\mathrm{W} \& \mathrm{~T}$ & $r_{t}^{n}+\psi_{\pi} \pi_{t}+\psi_{x} x_{t}$ & 0 & -68.94 & \\
\hline W & $r_{t}^{n}+\psi_{\pi} \pi_{t}$ & -1.90 & -80.58 & \\
\hline $\mathrm{T}$ & $\psi_{\pi} \pi_{t}+\psi_{x} x_{t}$ & $-12.50 * * *$ & -78.22 & \\
\hline South Korea & & & & -1226.80 \\
\hline W\&T & $r_{t}^{n}+\psi_{\pi} \pi_{t}+\psi_{x} x_{t}$ & 0 & -53.66 & \\
\hline $\mathrm{W}$ & $r_{t}^{n}+\psi_{\pi} \pi_{t}$ & $-24.40 * * *$ & -74.86 & \\
\hline $\mathrm{T}$ & $\psi_{\pi} \pi_{t}+\psi_{x} x_{t}$ & $-4.58^{*}$ & -65.26 & \\
\hline Sweden & & & & -1060.49 \\
\hline $\mathrm{W} \& \mathrm{~T}$ & $r_{t}^{n}+\psi_{\pi} \pi_{t}+\psi_{x} x_{t}$ & 0 & -27.90 & \\
\hline W & $r_{t}^{n}+\psi_{\pi} \pi_{t}$ & $-25.82 * * *$ & -43.06 & \\
\hline $\mathrm{T}$ & $\psi_{\pi} \pi_{t}+\psi_{x} x_{t}$ & $-5.32^{*}$ & -35.42 & \\
\hline Switzerland & & & & -743.35 \\
\hline $\mathrm{W} \& \mathrm{~T}$ & $r_{t}^{n}+\psi_{\pi} \pi_{t}+\psi_{x} x_{t}$ & 0 & -20.72 & \\
\hline W & $r_{t}^{n}+\psi_{\pi} \pi_{t}$ & $-16.52^{* * *}$ & -31.40 & \\
\hline $\mathrm{T}$ & $\psi_{\pi} \pi_{t}+\psi_{x} x_{t}$ & $-10.12^{* * *}$ & -33.14 & \\
\hline U.K. & & & & -981.72 \\
\hline $\mathrm{W} \& \mathrm{~T}$ & $r_{t}^{n}+\psi_{\pi} \pi_{t}+\psi_{x} x_{t}$ & 0 & -36.20 & \\
\hline W & $r_{t}^{n}+\psi_{\pi} \pi_{t}$ & $-12.50 * * *$ & -73.00 & \\
\hline $\mathrm{T}$ & $\psi_{\pi} \pi_{t}+\psi_{x} x_{t}$ & $-4.68^{*}$ & -35.50 & \\
\hline
\end{tabular}

Note: Each panel shows the pairwise model comparison results for all six countries in our dataset. For each, the table reports the log-marginal likelihood (ML) for the reference small open economy model under the W\&T rule in the last column. The table also includes the KR ratio for the three monetary policy variants under the small-open economy model relative to the small open economy specification with the W\&T rule in the third column and the KR ratio for the three monetary policy variants under the closed-economy specification relative to the small open economy model with the W\&T rule.

The second column of the table describes the target policy rate $\left(i_{t}^{*}\right)$ of the corresponding variant of the policy rule. Monetary policy contains a smoothing component and is implemented as follows: $i_{t}=\rho_{i} i_{t-1}^{*}+\left(1-\rho_{i}\right) i_{t}^{*}+\varepsilon_{i, t}$. 
Table 4: Parameter Estimation Results

\begin{tabular}{|c|c|c|c|c|c|c|c|}
\hline Name & Prior & Australia & Canada & South Korea & Sweden & Switzerland & UK \\
\hline \multirow[b]{2}{*}{$\varphi$} & 1.50 & 2.70 & 2.22 & 3.07 & 2.30 & 1.53 & 2.67 \\
\hline & {$[0.78,2.41]$} & {$[1.60,4.00]$} & {$[1.20,3.44]$} & {$[2.04,4.26]$} & {$[1.40,3.40]$} & {$[0.83,2.42]$} & {$[1.55,3.94]$} \\
\hline \multirow[b]{2}{*}{$\eta$} & 1.00 & 0.71 & 0.65 & 1.22 & 0.98 & 1.01 & 0.63 \\
\hline & {$[0.70,1.35]$} & {$[0.47,0.98]$} & {$[0.46,0.88]$} & {$[0.92,1.56]$} & {$[0.71,1.29]$} & {$[0.74,1.34]$} & {$[0.41,0.91]$} \\
\hline \multirow{2}{*}{$\psi_{\pi}$} & 1.50 & 1.38 & 1.95 & 1.40 & 1.41 & 2.00 & 1.83 \\
\hline & {$[0.78,2.41]$} & {$[1.07,1.91]$} & {$[1.44,2.60]$} & {$[1.09,1.84]$} & {$[1.10,1.90]$} & {$[1.51,2.60]$} & {$[1.37,2.41]$} \\
\hline \multirow{2}{*}{$\psi_{x}$} & 0.50 & 0.48 & 0.38 & 0.53 & 0.47 & 0.70 & 0.55 \\
\hline & {$[0.17,0.97]$} & {$[0.17,0.90]$} & {$[0.16,0.67]$} & {$[0.21,0.94]$} & {$[0.19,0.85]$} & {$[0.36,1.12]$} & {$[0.27,0.91]$} \\
\hline \multirow[b]{2}{*}{$\rho_{i}$} & 0.50 & 0.53 & 0.61 & 0.67 & 0.70 & 0.64 & 0.75 \\
\hline & {$[0.17,0.83]$} & {$[0.38,0.68]$} & {$[0.48,0.72]$} & {$[0.56,0.77]$} & {$[0.60,0.79]$} & {$[0.51,0.75]$} & {$[0.67,0.82]$} \\
\hline \multirow[b]{2}{*}{$\alpha$} & -- & 0.20 & 0.23 & 0.30 & 0.28 & 0.13 & 0.12 \\
\hline & {$[--,--]$} & {$[0.11,0.29]$} & {$[0.16,0.31]$} & {$[0.22,0.39]$} & {$[0.20,0.37]$} & {$[0.08,0.18]$} & {$[0.07,0.18]$} \\
\hline \multirow{2}{*}{$r^{s s}$} & 2.50 & 2.46 & 2.48 & 2.50 & 2.49 & 2.51 & 2.50 \\
\hline & {$[1.11,4.34]$} & {$[1.09,4.31]$} & {$[1.10,4.31]$} & {$[1.11,4.35]$} & {$[1.10,4.34]$} & {$[1.11,4.36]$} & {$[1.11,4.34]$} \\
\hline \multirow{2}{*}{$\kappa$} & 0.50 & 0.95 & 0.65 & 1.87 & 1.12 & 1.05 & 0.38 \\
\hline & {$[0.17,0.97]$} & {$[0.48,1.55]$} & {$[0.36,1.02]$} & {$[1.27,2.56]$} & {$[0.70,1.64]$} & {$[0.62,1.60]$} & {$[0.20,0.67]$} \\
\hline \multirow{2}{*}{$\tau$} & 0.50 & 0.48 & 0.44 & 0.71 & 0.63 & 0.44 & 0.26 \\
\hline & {$[0.17,0.83]$} & {$[0.28,0.70]$} & {$[0.29,0.63]$} & {$[0.54,0.87]$} & {$[0.46,0.81]$} & {$[0.30,0.61]$} & {$[0.14,0.47]$} \\
\hline \multirow[b]{2}{*}{$\rho_{q}$} & 0.40 & 0.53 & 0.42 & 0.12 & 0.34 & 0.10 & 0.06 \\
\hline & {$[0.10,0.75]$} & {$[0.41,0.65]$} & {$[0.30,0.55]$} & {$[0.03,0.23]$} & {$[0.21,0.47]$} & {$[0.02,0.20]$} & {$[0.01,0.13]$} \\
\hline \multirow[b]{2}{*}{$\rho_{z}$} & 0.20 & 0.04 & 0.04 & 0.02 & 0.03 & 0.02 & 0.07 \\
\hline & {$[0.06,0.39]$} & {$[0.01,0.08]$} & {$[0.01,0.08]$} & {$[0.01,0.03]$} & {$[0.01,0.07]$} & {$[0.01,0.05]$} & {$[0.02,0.14]$} \\
\hline \multirow[b]{2}{*}{$\rho_{g}$} & 0.20 & 0.30 & 0.31 & 0.39 & 0.33 & 0.51 & 0.24 \\
\hline & {$[0.06,0.39]$} & {$[0.11,0.51]$} & {$[0.12,0.52]$} & {$[0.18,0.59]$} & {$[0.13,0.54]$} & {$[0.28,0.71]$} & {$[0.08,0.46]$} \\
\hline \multirow[b]{2}{*}{$\rho_{y^{f}}$} & 0.90 & 0.90 & 0.92 & 0.96 & 0.93 & 0.93 & 0.89 \\
\hline & {$[0.81,0.97]$} & {$[0.85,0.94]$} & {$[0.89,0.95]$} & {$[0.94,0.98]$} & {$[0.88,0.96]$} & {$[0.90,0.96]$} & {$[0.84,0.92]$} \\
\hline \multirow[b]{2}{*}{$\rho_{\pi^{f}}$} & 0.80 & 0.35 & 0.33 & 0.32 & 0.44 & 0.34 & 0.38 \\
\hline & {$[0.61,0.94]$} & {$[0.25,0.46]$} & {$[0.23,0.44]$} & {$[0.22,0.43]$} & {$[0.33,0.55]$} & {$[0.23,0.45]$} & {$[0.27,0.49]$} \\
\hline \multirow[b]{2}{*}{$\rho_{u}$} & 0.80 & 0.95 & 0.92 & 0.97 & 0.97 & 0.96 & 0.94 \\
\hline & {$[0.61,0.94]$} & {$[0.91,0.98]$} & {$[0.88,0.96]$} & {$[0.95,0.99]$} & {$[0.95,0.99]$} & {$[0.94,0.98]$} & {$[0.91,0.97]$} \\
\hline \multirow[b]{2}{*}{$\sigma_{i}$} & 0.50 & 0.35 & 0.30 & 0.24 & 0.26 & 0.18 & 0.23 \\
\hline & {$[0.29,0.86]$} & {$[0.28,0.44]$} & {$[0.24,0.37]$} & {$[0.19,0.29]$} & {$[0.21,0.31]$} & {$[0.15,0.22]$} & {$[0.20,0.27]$} \\
\hline \multirow[b]{2}{*}{$\sigma_{q}$} & 1.50 & 2.66 & 1.66 & 2.48 & 1.34 & 1.09 & 1.25 \\
\hline & {$[0.90,2.50]$} & {$[2.41,2.92]$} & {$[1.51,1.83]$} & {$[2.25,2.73]$} & {$[1.22,1.48]$} & {$[0.99,1.21]$} & {$[1.13,1.38]$} \\
\hline \multirow[b]{2}{*}{$\sigma_{z}$} & 1.00 & 0.81 & 0.64 & 1.50 & 0.99 & 0.62 & 0.65 \\
\hline & {$[0.61,1.64]$} & {$[0.67,0.98]$} & {$[0.52,0.79]$} & {$[1.32,1.71]$} & {$[0.86,1.16]$} & {$[0.50,0.77]$} & {$[0.50,0.84]$} \\
\hline \multirow[b]{2}{*}{$\sigma_{y^{f}}$} & 1.50 & 3.19 & 2.63 & 1.72 & 1.75 & 1.43 & 2.15 \\
\hline & {$[1.05,2.15]$} & {$[1.49,5.95]$} & {$[1.42,4.50]$} & {$[1.19,2.44]$} & {$[1.18,2.56]$} & {$[1.03,2.00]$} & {$[1.15,4.674]$} \\
\hline \multirow[b]{2}{*}{$\sigma_{\pi^{f}}$} & 0.55 & 4.11 & 2.33 & 5.09 & 2.59 & 2.06 & 2.95 \\
\hline & {$[0.33,0.92]$} & {$[3.72,4.55]$} & {$[2.11,2.57]$} & {$[4.60,5.62]$} & {$[2.35,2.86]$} & {$[1.87,2.28]$} & {$[2.67,3.26]$} \\
\hline \multirow[b]{2}{*}{$\sigma_{u}$} & 0.55 & 0.71 & 0.73 & 0.52 & 0.59 & 0.44 & 0.48 \\
\hline & {$[0.33,0.92]$} & {$[0.43,1.13]$} & {$[0.47,1.09]$} & {$[0.33,0.79]$} & {$[0.38,0.90]$} & {$[0.31,0.64]$} & {$[0.33,0.70]$} \\
\hline \multirow[b]{2}{*}{$\sigma_{g}$} & 0.25 & 0.18 & 0.18 & 0.16 & 0.18 & 0.18 & 0.21 \\
\hline & {$[0.14,0.43]$} & {$[0.12,0.26]$} & {$[0.12,0.25]$} & {$[0.11,0.22]$} & {$[0.12,0.26]$} & {$[0.12,0.28]$} & {$[0.13,0.33]$} \\
\hline
\end{tabular}

Note: The table reports posterior means and $90 \%$ confidence intervals (in brackets) which are computed from 4 MCMC chains of 250,000 draws each of which 62,500 draws were used as an initial burn-in phase. Convergence diagnostic were assessed using trace plots, $\mathrm{R}$ statistics, and SPM tests. The prior mean of the degree of openness, $\alpha$, varies from country to country as reported in Table 2. 


\section{Table 5: Comovement with U.S. Natural Rate Estimates}

\begin{tabular}{cccccc}
\hline \hline Australia & Canada & South Korea & Sweden & Switzerland & U.K. \\
\hline 0.74 & 0.82 & 0.81 & 0.79 & 0.61 & 0.86 \\
\hline
\end{tabular}

Note: Entries are calculated by the aggregate correlation between the natural rate of interest of each small open economy and five U.S. natural rate estimates for the period between 1983Q1 and 2016Q3 with the Fisher transformation method described in David (1949).

\section{Table 6: Contribution to the Natural Interest Rates}

\begin{tabular}{|c|c|c|c|c|c|c|}
\hline Name & Australia & Canada & South Korea & Sweden & Switzerland & UK \\
\hline \multicolumn{7}{|l|}{ Period 1} \\
\hline \multirow{2}{*}{ Technology } & 7.12 & 5.12 & 9.11 & 11.20 & 6.95 & 14.10 \\
\hline & {$[0.57,19.77]$} & {$[0.33,15.86]$} & {$[1.36,24.35]$} & {$[0.89,31.45]$} & {$[0.50,20.01]$} & {$[1.00,39.23]$} \\
\hline \multirow{2}{*}{ Foreign Output } & 57.34 & 52.21 & 13.87 & 26.97 & 22.77 & 49.89 \\
\hline & {$[34.92,78.67]$} & {$[31.12,72.29]$} & {$[3.56,31.67]$} & {$[6.93,54.33]$} & {$[7.44,43.31]$} & {$[23.85,74.37]$} \\
\hline \multirow{2}{*}{ Preference } & 35.54 & 42.67 & 77.02 & 61.83 & 70.29 & 36.01 \\
\hline & {$[16.58,58.87]$} & {$[22.83,64.07]$} & {$[56.69,91.83]$} & {$[35.31,84.60]$} & {$[48.36,87.56]$} & {$[15.00,61.04]$} \\
\hline \multicolumn{7}{|l|}{ Period 8} \\
\hline \multirow{2}{*}{ Technology } & 2.61 & 1.85 & 5.18 & 5.83 & 3.39 & 6.41 \\
\hline & {$[0.19,7.69]$} & {$[0.11,6.47]$} & {$[0.67,13.60]$} & {$[0.42,17.17]$} & {$[0.21,10.00]$} & {$[0.36,20.59]$} \\
\hline \multirow{2}{*}{ Foreign Output } & 83.00 & 81.43 & 42.22 & 58.05 & 50.19 & 77.06 \\
\hline & {$[68.47,92.86]$} & {$[67.01,91.35]$} & {$[17.59,67.89]$} & {$[28.55,82.00]$} & {$[25.17,72.30]$} & {$[55.47,90.76]$} \\
\hline \multirow{2}{*}{ Preference } & 14.39 & 16.72 & 52.60 & 36.11 & 46.42 & 16.53 \\
\hline & {$[5.83,28.25]$} & {$[7.64,29.76]$} & {$[28.62,76.63]$} & {$[15.18,63.61]$} & {$[25.64,70.56]$} & {$[6.37,33.10]$} \\
\hline \multicolumn{7}{|l|}{ Period 20} \\
\hline \multirow{2}{*}{ Technology } & 2.21 & 1.48 & 4.05 & 4.84 & 2.84 & 5.73 \\
\hline & {$[0.16,6.59]$} & {$[0.08,5.37]$} & {$[0.49,10.81]$} & {$[0.34,14.30]$} & {$[0.17,8.54]$} & {$[0.32,18.80]$} \\
\hline \multirow{2}{*}{ Foreign Output } & 85.58 & 85.20 & 54.66 & 65.23 & 58.28 & 79.60 \\
\hline & {$[72.47,94.03]$} & {$[73.24,93.36]$} & {$[29.53,77.76]$} & {$[38.20,85.44]$} & {$[34.50,77.90]$} & {$[60.10,91.90]$} \\
\hline \multirow{2}{*}{ Preference } & 12.20 & 13.32 & 41.29 & 29.93 & 38.88 & 14.67 \\
\hline & {$[4.99,24.25]$} & {$[5.97,24.57]$} & {$[20.48,65.28]$} & {$[12.47,54.71]$} & {$[20.07,61.79]$} & {$[5.60,29.33]$} \\
\hline \multicolumn{7}{|l|}{ Period Infinity } \\
\hline \multirow{2}{*}{ Technology } & 2.21 & 1.43 & 3.45 & 4.58 & 2.70 & 5.67 \\
\hline & {$[0.16,6.52]$} & {$[0.08,5.25]$} & {$[0.40,8.98]$} & {$[0.32,13.40]$} & {$[0.16,8.17]$} & {$[0.32,18.63]$} \\
\hline \multirow{2}{*}{ Foreign Output } & 85.86 & 85.75 & 61.39 & 67.02 & 60.36 & 79.80 \\
\hline & {$[72.74,94.22]$} & {$[74.06,93.69]$} & {$[40.52,80.89]$} & {$[43.25,85.80]$} & {$[37.50,79.11]$} & {$[60.34,92.01]$} \\
\hline \multirow{2}{*}{ Preference } & 11.97 & 12.82 & 35.16 & 28.41 & 36.94 & 14.53 \\
\hline & {$[4.83,24.01]$} & {$[5.62,23.82]$} & {$[17.35,55.51]$} & {$[11.91,50.46]$} & {$[18.93,58.60]$} & {$[5.55,29.01]$} \\
\hline
\end{tabular}

Note: Entries decompose the forecast error variance of the natural rates of interest of each of the six countries in our dataset into percentages due to each shock at different forecast horizons. The table reports posterior means and $90 \%$ confidence intervals of each shock contribution (in brackets) onequarter ahead, eight-quarters ahead (two-years ahead), twenty-quarters ahead (five-years ahead), and the limit case where the forecasting horizon tends to infinity. 
Figure 1: Open vs. Closed KR Ratio
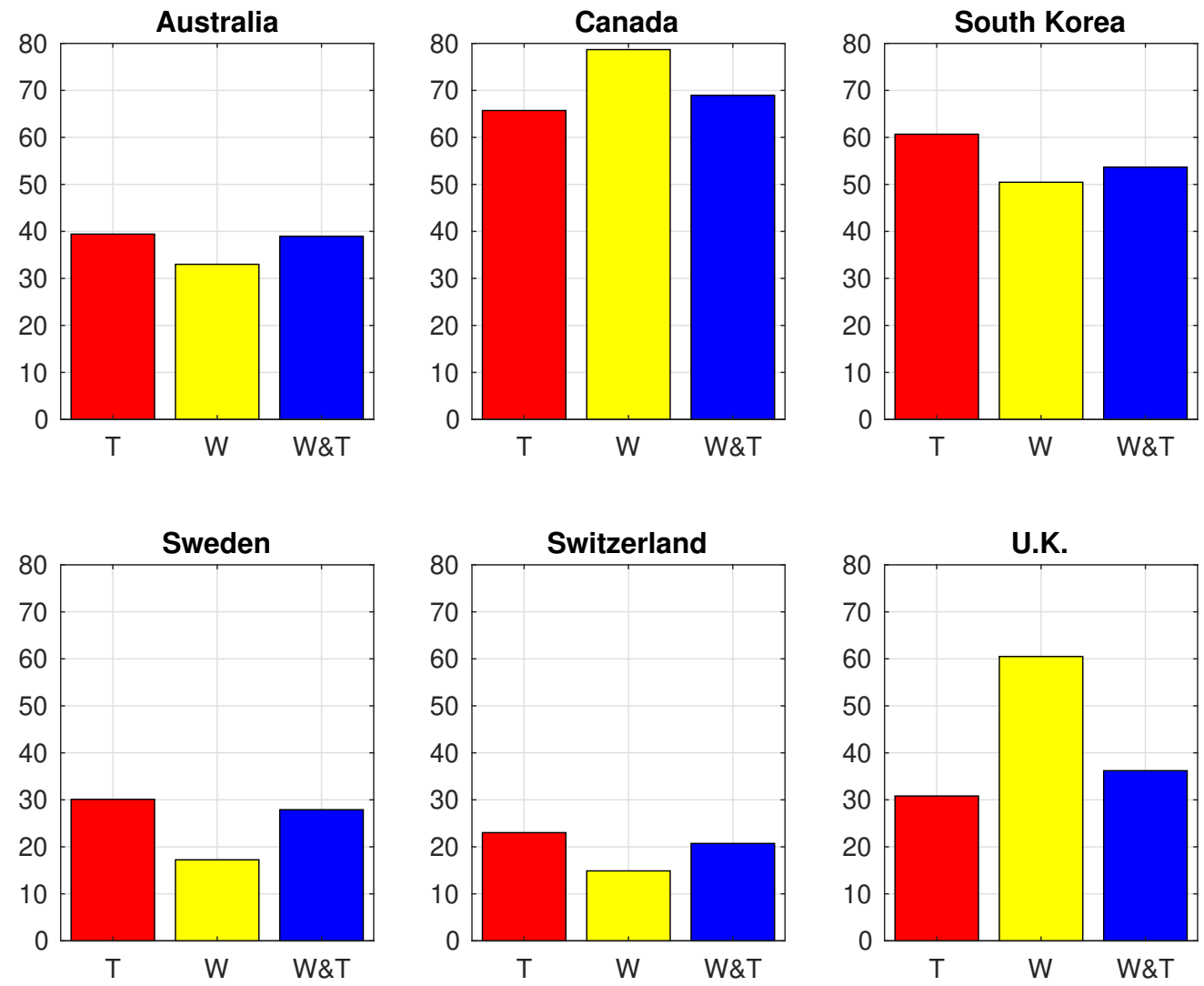

Note: Figure shows the Kass and Raftery (1995) KR ratio (defined as $K R=2\left(M L_{A}-M L_{B}\right.$ ), where $M L_{A}$ is the log of the marginal likelihood of the estimated model A (the small open-economy model) and $M L_{B}$ is the log of the marginal likelihood of the estimated model $\mathrm{B}$ (the closed economy specification where $\alpha=0$ ). Model A is compared against model $\mathrm{B}$ under alternative specifications of the monetary policy rule: the Taylor rule ("T"), the Wicksell rule ("W"), and the generalized rule ("W\&T"). Values of the KR ratio in excess of 10 are considered "very strong" evidence in favor of model A, i.e., in favor of the small open-economy specification. 
Figure 2: Impulse Response Functions (IRFs)
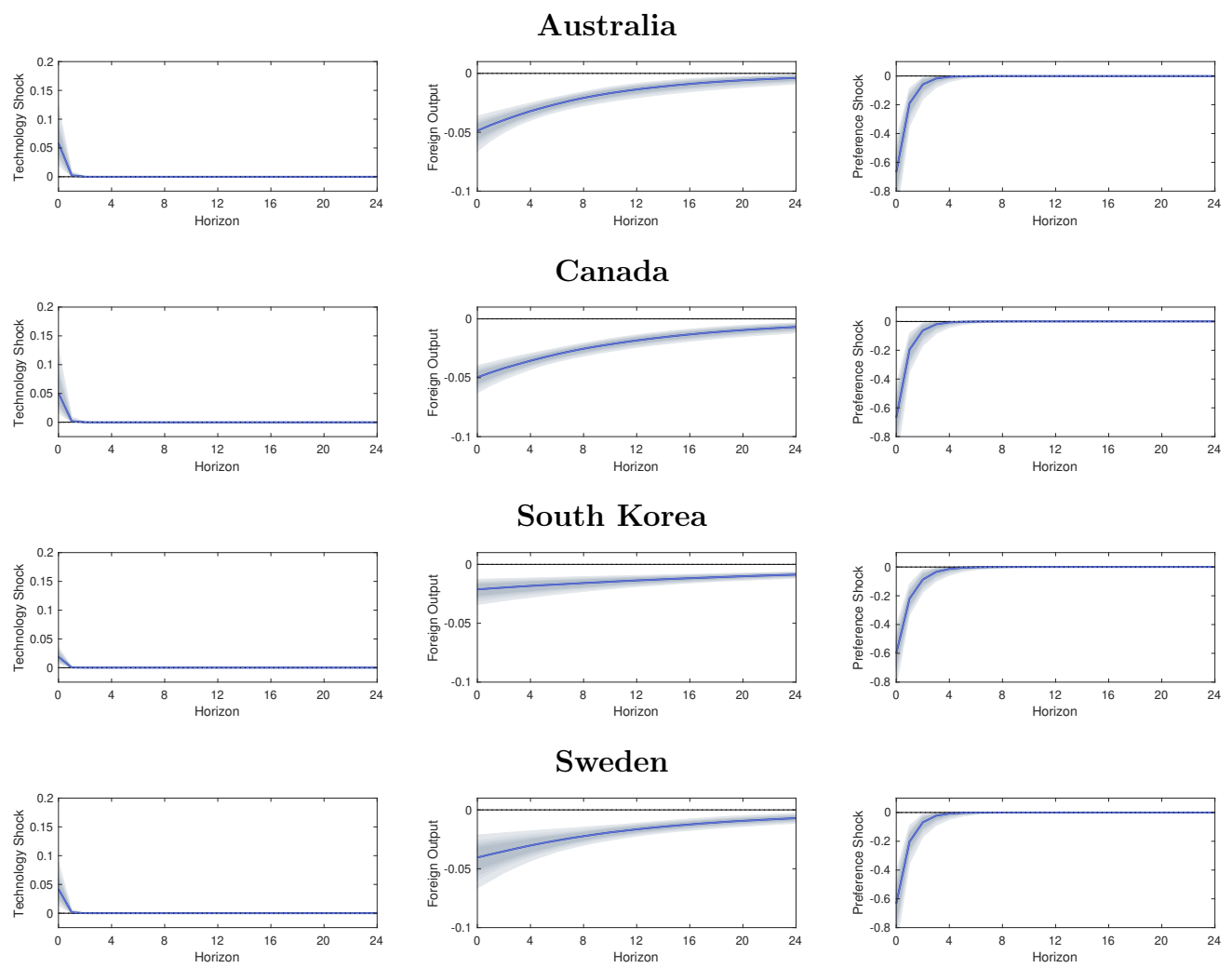

Sweden
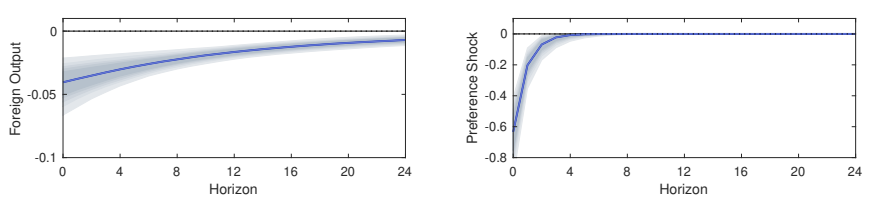

Switzerland
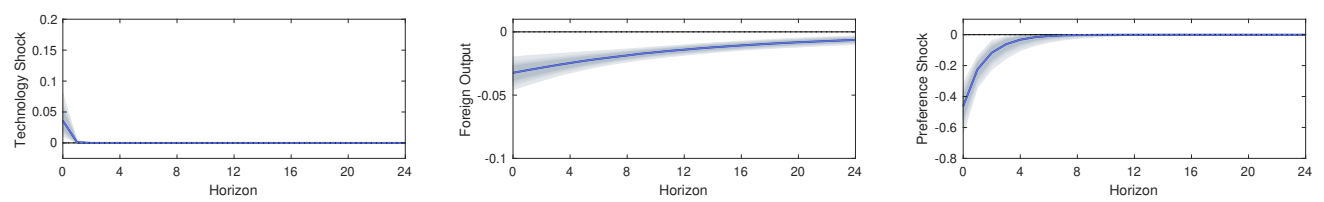

U.K.
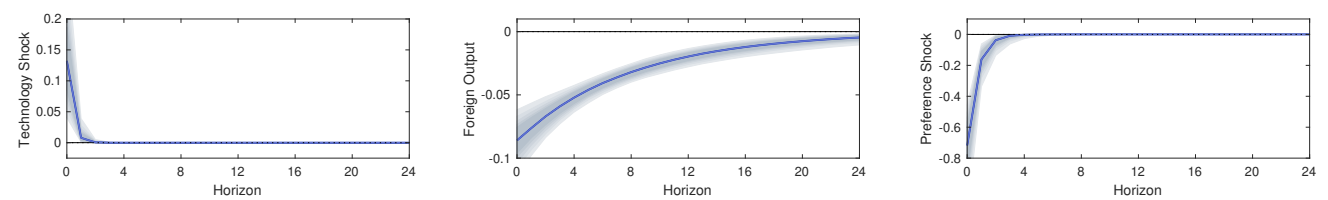

Note: Impulse response functions for response of estimated natural rates to technology, foreign output, and preference shocks. The impulse response functions are reported for each of the six countries in our dataset. 
Figure 3: Natural Rates Open vs. Closed Economy
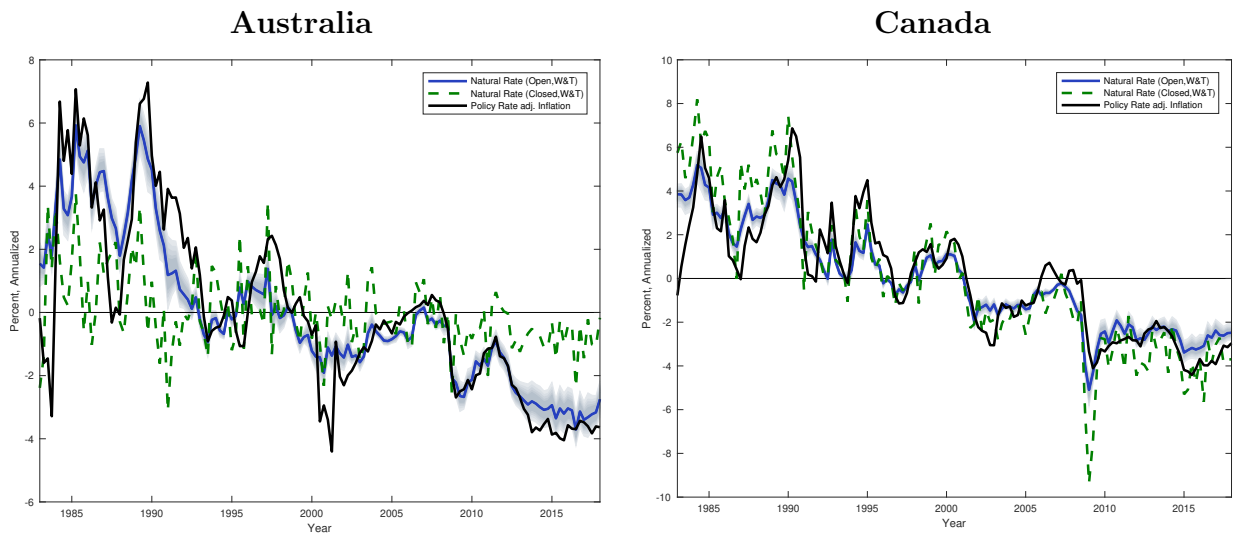

South Korea
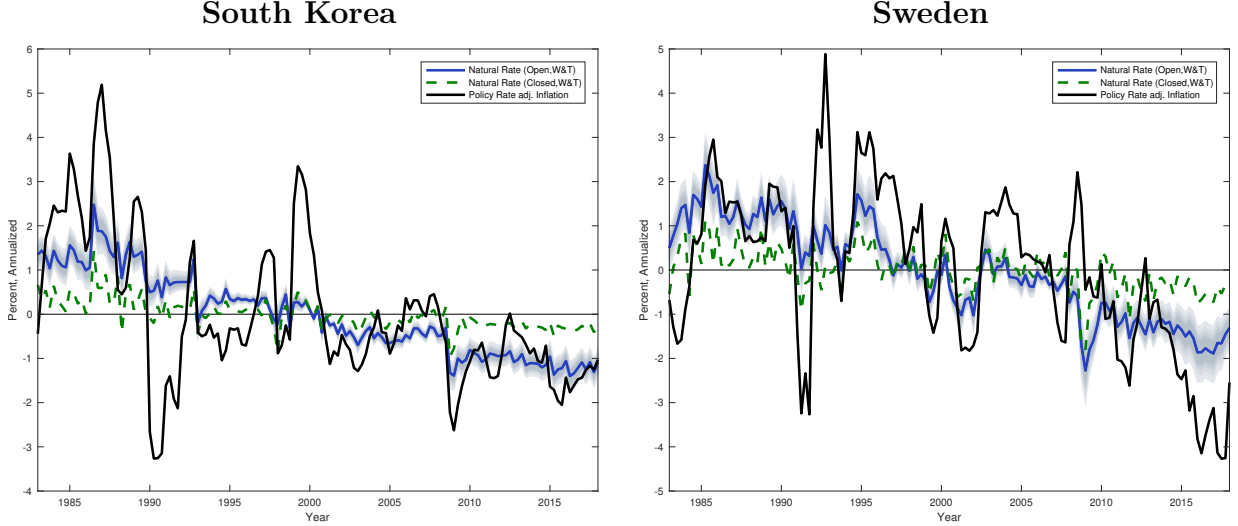

Switzerland

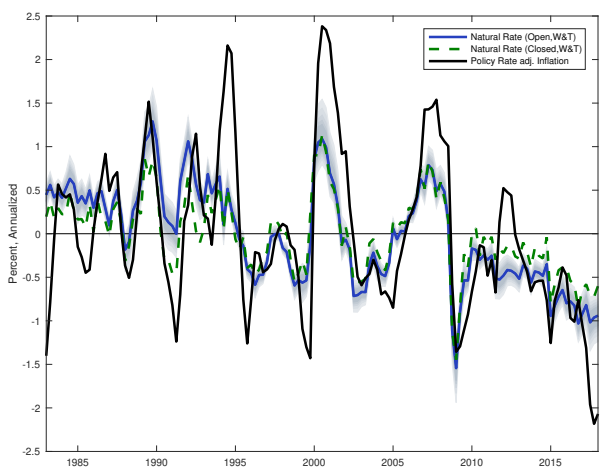

U.K.

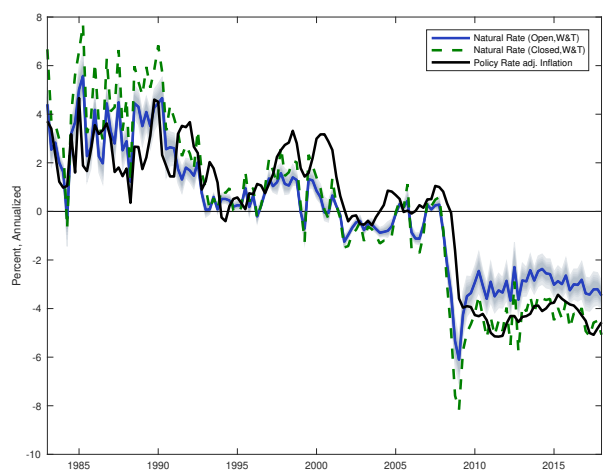

Note: The figure plots the recovered natural rate estimates under the reference model (a small open economy model with a W\&T monetary policy rule) with its corresponding $90 \%$ confidence intervals (blue line and shaded area) for all six countries in our dataset. Together with this, the model reports the estimated natural rate of interest under the W\&T rule but assuming a closed economy specification instead (green dashed lines). The comparison between the estimate of the reference model and the closed-economy alternative illustrates the bias in the estimation of the natural rate of interest that arises whenever the estimated model is misspecified imposing that $\alpha=0$. The figure also plots the real interest rate computed as the nominal policy rate less inflation over the previous four quarters (black solid lines). The rates are demeaned and expressed in percentages at an annualized rate. 
Figure 4: Nominal Interest Rates Comparison

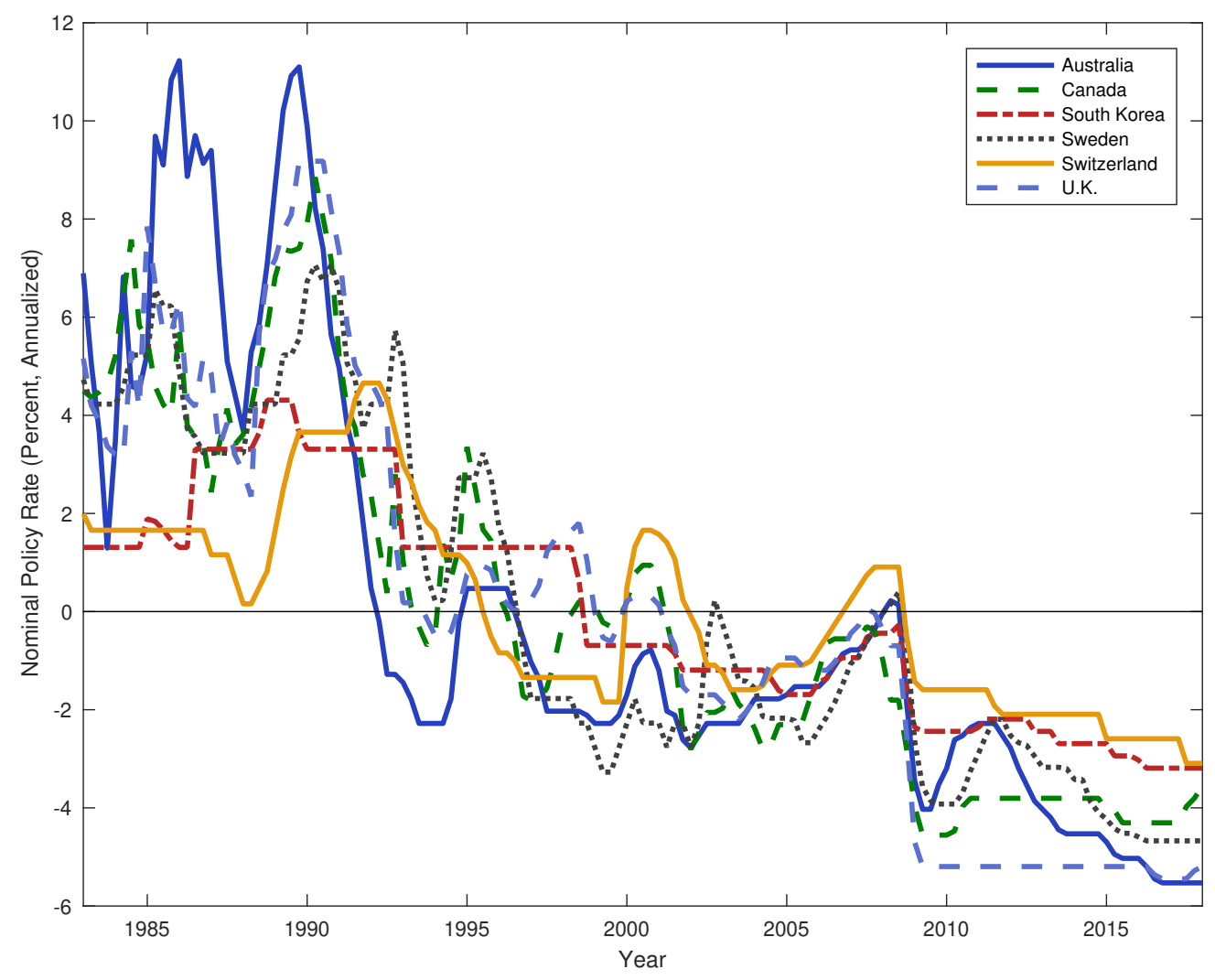

Note: The figure plots the demeaned nominal interest rates of the six small open economies in our dataset and illustrates their pattern of comovement. 
Figure 5: Natural Interest Rate Comparison

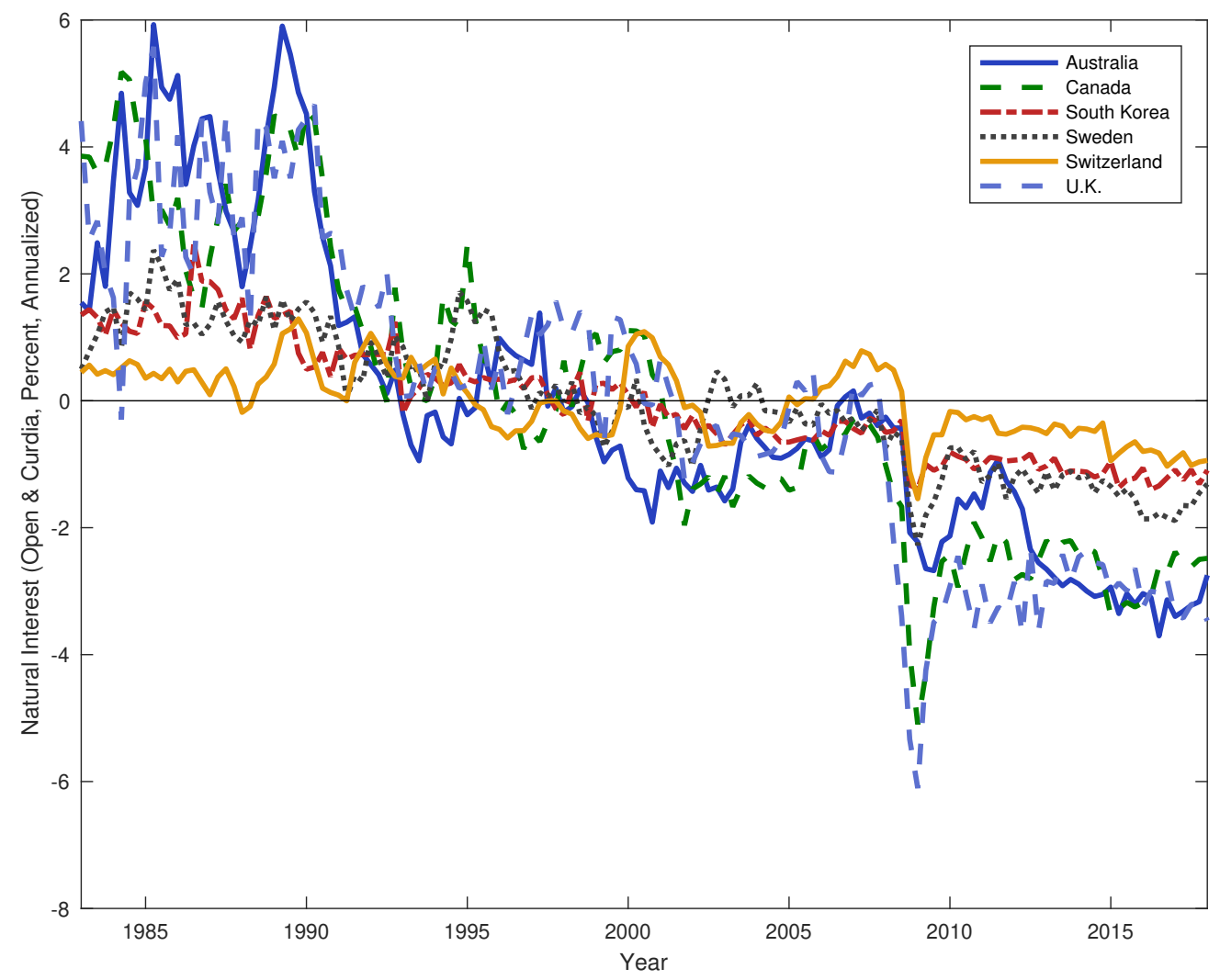

Note: The figure plots the smoothed posterior median estimates of the natural rates of interest recovered under the reference model (a small open economy under the W\&T rule) for each of the six small open economies in our dataset and illustrates their pattern of comovement. The figure also shows the significant downward drift of the natural rates over time (particulary since the Global Financial Crisis of 2007-2009). 
Figure 6: Real Interest Rate Gap (W\&T, Open-Economy) Comparison

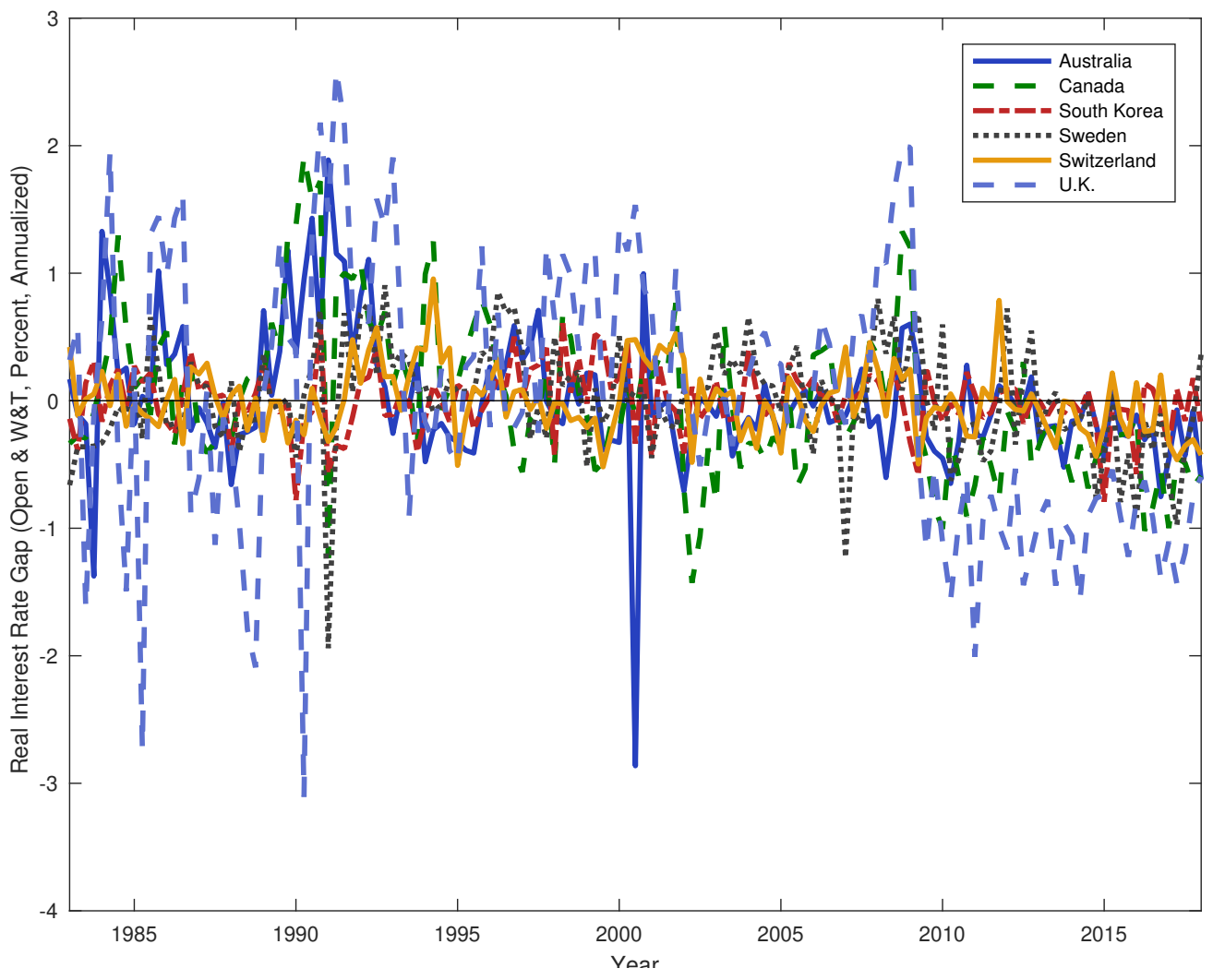

Note: The figure plots the estimate of the natural rate gaps implied by the reference model (a small open economy under the W\&T rule) for each of the six small open economies in our dataset and illustrates their pattern of variability (volatility) and also their weak comovement. 